\title{
Therapeutic Communities for Addictions: A Review of Their Effectiveness from a Recovery-Oriented Perspective
}

\author{
Wouter Vanderplasschen, ${ }^{1}$ Kathy Colpaert, ${ }^{1}$ Mieke Autrique, ${ }^{1}$ Richard Charles Rapp, ${ }^{2}$ \\ Steve Pearce, ${ }^{3}$ Eric Broekaert, ${ }^{1}$ and Stijn Vandevelde ${ }^{4}$ \\ ${ }^{1}$ Department of Orthopedagogics, Ghent University, H. Dunantlaan 2, 9000 Ghent, Belgium \\ ${ }^{2}$ Boonshoft School of Medicine, Center for Interventions, Treatment and Addictions Research (CITAR), Wright State University, \\ 3640 Colonel Glenn Highway, Dayton, OH 45435, USA \\ ${ }^{3}$ Oxfordshire Complex Needs Service, Oxfordshire and Buckinghamshire Mental Health NHS Foundation Trust, Manzil Way, \\ Oxford OX4 1XE, UK \\ ${ }^{4}$ Faculty of Education, Health and Social Work, University College Ghent, 9000 Ghent, Belgium
}

Correspondence should be addressed to Wouter Vanderplasschen; wouter.vanderplasschen@ugent.be

Received 28 October 2012; Accepted 9 December 2012

Academic Editors: V. Di Michele, S. M. Dursun, and T. Shioiri

Copyright (C) 2013 Wouter Vanderplasschen et al. This is an open access article distributed under the Creative Commons Attribution License, which permits unrestricted use, distribution, and reproduction in any medium, provided the original work is properly cited.

\begin{abstract}
Therapeutic communities (TCs) for addictions are drug-free environments in which people with addictive problems live together in an organized and structured way to promote change toward recovery and reinsertion in society. Despite a long research tradition in TCs, the evidence base for the effectiveness of TCs is limited according to available reviews. Since most of these studies applied a selective focus, we made a comprehensive systematic review of all controlled studies that compared the effectiveness of TCs for addictions with that of a control condition. The focus of this paper is on recovery, including attention for various life domains and a longitudinal scope. We searched the following databases: ISI Web of Knowledge (WoS), PubMed, and DrugScope. Our search strategy revealed 997 hits. Eventually, 30 publications were selected for this paper, which were based on 16 original studies. Two out of three studies showed significantly better substance use and legal outcomes among TC participants, and five studies found superior employment and psychological functioning. Length of stay in treatment and participation in subsequent aftercare were consistent predictors of recovery status. We conclude that TCs can promote change regarding various outcome categories. Since recovering addicts often cycle between abstinence and relapse, a continuing care approach is advisable, including assessment of multiple and subjective outcome indicators.
\end{abstract}

\section{Introduction}

Drug addiction is a complex mental health problem that is often associated with difficulties in various life domains such as unemployment, homelessness, relational conflicts, problems with the courts, and psychiatric comorbidity $[1,2]$. While some of these problems certainly evolve from the abuse of substances, many eventual addicts suffer from these problems prior to the onset of their drug use [3]. In both cases, drug addiction has generally been treated as an acute condition during brief episodes of residential care or several months of outpatient treatment, where the primary if not exclusive focus has been on abstinence to the exclusion of other concerns [4]. In contrast, addiction is increasingly regarded as a chronic relapsing disorder where recovery is possible [5], but often the one that requires intensive or even multiple treatment episodes and/or strong personal or community resources. A continuing care approach is needed to initiate and maintain recovery $[6,7]$. The recovery movement focuses on individuals' perceived needs and objectives and sees abstinence as a potential resource, but not as a prerequisite, for recovery [8-10]. A recovery-oriented approach in addiction research implies attention for the evolutions on various life domains and individuals' subjective 
well being as well as the adoption of a longitudinal perspective to understand the complexity of individuals' substance use careers and recovery processes [11].

A wide range of treatment and support services are available for persons with alcohol or drug addiction problems: detox programs, drug-free outpatient treatment, methadone maintenance therapy, long-term residential treatment programs, and harm reduction services. Therapeutic communities (TCs) for addictions, also called drug-free or concept TCs, aim at the reinsertion into society of former drug addicts and were one of the first specialized treatment initiatives for individuals with addiction problems, that evolved outside-and often in reaction to-the traditional mental health care. The TC history dates back to Synanon, a selfsupporting community of ex-addicts founded in 1958 in Santa Monica (California) [12]. A TC can be defined as "a drug-free environment in which people with addictive problems live together in an organized and structured way to promote change toward a drug-free life in the outside society" [13]. Until the mid-1980s, TCs had a predominant position in most Western addiction treatment systems, but due to the drug and HIV epidemic larger scale harm reduction initiatives (e.g., methadone maintenance, needle exchange programs) became the central focus of most West European drug policies. Despite the long-standing and worldwide availability of TC treatment, TCs were criticized for their limited coverage of drug addicts, the high costs of long-term residential treatment, and the lack of evidence of effectiveness resulting from randomized controlled trials. Moreover, high drop-out and relapse rates, altered client expectations and social norms and criticism on the impact of lengthy stays in closed communities further questioned the appropriateness of TC treatment around the turn of the century [14].

Although outpatient, medically-assisted (substitution) therapy is currently the most common addiction treatment modality $[15,16]$, one out of three clients in the European Union is engaging in other types of treatment, including therapeutic communities [17]. Recovery-oriented treatment in TCs starts from the widely accepted concept "community as a method" [18] and has been implemented on all continents. The standard TC model has been modified to address the needs of specific populations (e.g., women with children, persons with comorbid psychiatric disorders) or new phenomena (e.g., TCs in prisons, methadone substitution during TC treatment) in the so-called modified TCs (MTC) [19]. The TC method and objectives match well with the emerging recovery movement, since TC treatment can be regarded as an educational process where individuals are supported on their personal journey towards recovery and a drug-free lifestyle and to gain back control over their own lives [20].

Despite a long research tradition in TCs $[21,22]$, the evidence base for the effectiveness of TCs is limited according to the prevailing Cochrane hierarchy of scientific evidence [23]. Available reviews have been biased by a selective focus on some types of TCs or study designs and a predominant focus on drug abstinence. The frequently cited Cochrane review by Smith and colleagues [23] only included randomized trials, while random group allocation appeared to be either not feasible (i.e., significantly higher drop-out among controls) or advisable (i.e., motivation and self-selection are considered to be crucial ingredients of the treatment process) in several studies [24, 25]. Consequently, this meta-analysis included some studies without true randomization and excluded a large number of good quality quasi-experimental studies. A recent review by Malivert and colleagues [26] left out studies on prison TCs, while this type of modified TC has been the most frequently studied TC model during the last decade. Moreover, abstinence and treatment completion were the sole outcome measures in this study. Finally, the meta-analysis by Lees and colleagues [27] can be regarded as outdated, as it does not include any published study since 1999 .

Since sound scientific evidence is needed to inform service users, treatment providers, and policy makers about TCs' potential to promote recovery, the aim of this paper is to review the effectiveness of TCs for addictions, based on a comprehensive systematic review of available randomized and nonrandomized controlled studies. The paper is limited to studies with a controlled design, as these are robust study designs that generate a high level of evidence. Also, nonrandomized studies were included, since the number of randomized studies was very small $(n=5)$ and true randomization was compromised in several studies. Given the focus on recovery, a range of outcome measures-apart from abstinence-will be evaluated and a long-term outcome perspective will be applied, including an assessment of the influence of aftercare or continuing support.

\section{Methods}

This narrative review focuses on controlled studies (randomized trials as well as quasi-experimental designs) of therapeutic communities for addictions. We opted for a narrative review instead of a meta-analysis, given the heterogeneity of the study methodologies and the variety in data reporting. Studies were eligible if they met the following inclusion criteria.

(i) Intervention: therapeutic communities for the treatment of drug addiction that are long-term hierarchically structured (residential) educational environments, where former drug users live together and work towards recovery, and which are based on selfhelp and mutual help principles [12, 21].

(ii) Target population: adults addicted to illegal drugs (mostly heroin, cocaine, or amphetamines), often in combination with an addiction to other (legal) substances (e.g., alcohol, prescription drugs). Studies including persons with comorbid psychiatric disorders were eligible, if all study participants had a drug addiction.

(iii) Outcome measures: at least one of the following (nonexhaustive) list of outcome measures was reported: substance use (illicit drug use, alcohol use), length of stay in treatment (retention, treatment completion/drop-out), employment status, criminal involvement, health and well being, family relations, quality of life, treatment status, mortality, and so forth. Objective (describing the actual situation) and 
subjective (indicating individuals' personal perspective) indicators were considered, as well as selfreport measures, biological markers, and administrative data.

(iv) Study design: randomized controlled trials and quasiexperimental studies that have compared prospectively residents that followed TC treatment with a control group that was treated in a usual care setting ("treatment as usual"/standard of care) or another type of TC (e.g., shorter program/day TC) or with a control group out of treatment (e.g., in prison/waitlist controls). Studies needed to report findings on TC outcomes separately from these of other types of interventions (e.g., aftercare).

Available reviews and meta-analyses were not included, but all studies selected for the reviews were screened based on the aforementioned inclusion criteria. Studies that did not focus on TC treatment, but on another type of residential care, were excluded from the paper. If several publications concerned the same baseline sample and study design, these publications were regarded as one single study.

2.1. Search Strategy. We searched the following databases: ISI Web of Knowledge (WoS), PubMed, and DrugScope, up to December 31, 2011. There were no language, country, or publication year restrictions. Search strategies were developed for each database, based on the search strategy developed for ISI Web of Knowledge, but were revised accordingly to take into account differences in controlled vocabulary and syntax rules. The key words we searched for were "therapeutic communit" AND "drug* or addict" or dependen* or substance use" AND "outcome* or evaluation or follow-up or effectiveness." The reference lists of retrieved studies and of available reviews were checked for relevant studies. In addition, the index of the International Journal of Therapeutic Communities, a specialized peer-reviewed journal on therapeutic communities and other supportive organisations, was screened for relevant publications.

Our search strategy revealed 997 hits, which resulted in a first selection of 185 records, based on title and abstract (see Figure 1). Thorough analysis of these abstracts by two independent reviewers (Mieke Autrique and Wouter Vanderplasschen) led to the selection of 46 studies.

In addition to the database search, conference abstracts of European Federation of Therapeutic Communities (EFTC), World Federation of Therapeutic Communities (WFTC), and European Working Group on Drugs Oriented Research (EWODOR) conferences and the grey literature were scanned for relevant (un)published studies. We made a search of the registry of ongoing clinical trials to identify any ongoing RCTs. In case a publication could not be tracked through the Ghent University online library system, the study authors were contacted for a copy of the original manuscript. Finally, TC experts in various countries as well as the European Monitoring Centre for Drugs and Drug Addiction (EMCDDA) national focal points were contacted to retrieve additional (un)published or ongoing studies that have assessed the effectiveness of TCs for addictions.
2.2. Study Selection. In total, 46 controlled studies were identified ( 28 based on the previously mentioned search strategy and 18 additional titles were selected based on the reference lists of selected studies and available reviews). After reading the full texts of these articles, 16 studies were excluded, because only in-treatment outcomes were reported $(n=1)$, because the treatment provided was not in line with the TC definition we put forward ( $n=1)$, or because the study design was deemed not a controlled design $(n=8)$. Four studies were excluded as they concerned secondary analyses of previously published data, usually with a focus on a specific subsample. Two studies did not compare TC treatment with a control intervention but rather compared outcomes related to specific client characteristics.

2.3. Data Extraction and Analysis. Two reviewers (Mieke Autrique and Wouter Vanderplasschen) extracted data on the characteristics and results from the selected studies into a large summary table (cf. Table 1). The following study characteristics were extracted: (1) author, country (state), and year of publication; (2) type of study design and timing of follow-up measurements; (3) inclusion criteria and characteristics of the study participants + attrition rates at followup; (4) type of TC (including length of treatment) and type of control condition; and (5) outcome categories: retention and completion rates, substance use outcomes (drug and alcohol use), criminal involvement, employment, and other outcomes like health status, housing situation, and a column including determinants/correlates of abstinence/retention. Findings from studies including multiple follow-up assessments were grouped and numbered accordingly (cf. Table 1). We compared reported outcomes in various categories at all reported follow-up moments post treatment (cf. Table 2.). In this summary table, "+" indicates a significant difference regarding the outcome category in favor of the experimental condition, while "-" indicates a significant difference in favor of the control group. "=" means that no significant between group differences were reported; alternatively text can be rephrased as follows: that no significant differences were reported between the experimental and the control group.

\section{Results}

Based on our review of controlled studies of TC effectiveness, we identified 30 publications that included a longitudinal evaluation of TCs for addictions and applied a prospective controlled study design (cf. Table 1). These 30 publications are based on-in total-16 original studies, since several articles referred to the same (large) study and/or to various measurements regarding one single study (e.g., the Delaware study (no. 7) by Inciardi and colleagues [28-32]; the Amity prison study (no. 8) by Prendergast and colleagues [3335]). Thorough methodological screening revealed that only five studies could be regarded as truly randomized (cf. Table 1), since in most studies the random group allocation process was compromised at some point $[25,36]$ or was not possible/advisable at all $[24,37,38]$. The methodological quality of the studies varied but was often rather poor due to high attrition rates, lack of objective verification of study 


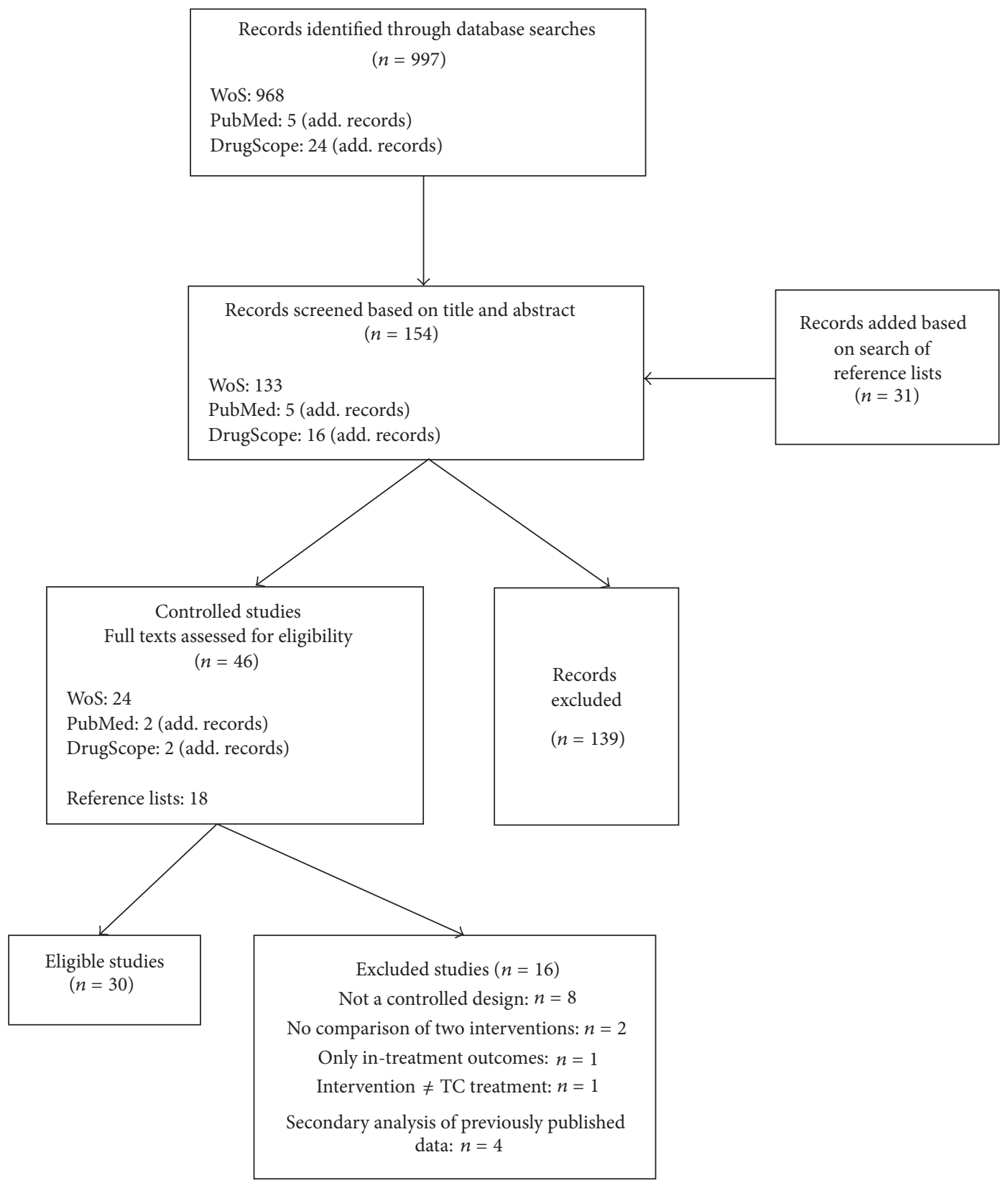

FIGURE 1: Flowchart of the search process and number of studies retained/excluded in each phase.

findings, and a focus on one single study site (cf. Table 1). The oldest controlled studies date back to the beginning of the 1980s [39-41]. The bulk of studies has been carried out/published in the 1990s. All controlled studies have been performed in the United States. Despite a growing research tradition in Europe, Australia, and South America, only observational uncontrolled studies have been carried out on these continents.

The follow-up period in most controlled studies is between 6 and 24 months, and only three studies have followed participants for more than 36 months. Study outcomes may vary according to the follow-up moment $[24,25,33]$, but usually the magnitude of the difference(s) between the experimental and control group diminished over time (cf. Table 2). Overall, great within-group reductions in problem severity were observed between baseline and followup assessments, in particular regarding drug use, criminal involvement, and employment. The two outcome measures that were assessed in most studies are "substance use" and "criminal involvement." All included studies reported at least one outcome measure in one of both categories. Eight out of 13 (note that this number is lower than 16, as not all studies reported outcomes concerning all categories) studies reported at least one positive significant difference between 
the TC and control group regarding legal outcomes at the one-year follow-up, while 9/14 studies found significantly better substance use outcomes among the TC group at that time (cf. Table 2). All studies included multiple outcome indicators (also within one category), but only one study succeeded to find several significant, positive outcomes regarding most legal outcome measures (i.e., reincarceration rate, days to first illegal activity/incarceration, and length of prison sentence) [34]. Most studies found only one significant between group difference per category (e.g., time to drug relapse), while other outcome indicators within this category did not differ between groups (cf. Table 1). Significantly better outcomes in one category (e.g., substance use, criminal involvement) are not necessarily accompanied by improved outcomes on other domains (e.g., employment, psychological health). Only four studies found significant differences regarding three or more outcome categories [24, 32, 42, 43].

3.1. Treatment Retention, Health, and Social Functioning. As opposed to all other outcome categories, TC participants scored worse in comparison with controls on treatment retention/completion. Only two studies showed higher retention rates for the TC group, while three studies found significantly worse completion rates among TC-participants, and six studies found non-significant between group differences, mostly in favor of the control condition (cf. Table 1). Substantial drop-out has been observed in most long-term TC programs, especially in the early phases of treatment [48]. Studies that have compared longer and shorter TC programs usually found lower completion rates in longer and more intensive programs $[38,51]$.

Five out of six studies that have reported employment outcomes found significantly better employment rates among TC participants. Also, five studies (out of 7) showed superior outcomes on psychological symptoms, as compared with controls. Other outcomes that were studied are risk behavior $(n=1)$ and family and social relations $(n=2)$, which were found to be better in two studies [32, 48].

3.2. Substance Use Outcomes. Although TC participants had at some point posttreatment better substance use outcomes than controls in 10 studies, substance use levels varied greatly and overall, between $25 \%$ and $55 \%$ of the respondents relapsed to drug use after 12 to 18 months. Some studies found very low initial relapse rates (e.g., 4\% [38], 9\% [42] and $15 \%$ [43]), while others found much higher relapse rates (e.g., $53 \%$ [34] and 69\% [29]). Usually, time to relapse was longer among TC participants [52]. One of the few controlled studies that followed prison TC-participants up to three years after their release found a relapse rate of $77 \%$ in the TC and $94 \%$ in the control condition [29]. Lower relapse rates were usually associated with longer treatment exposure (length of stay in treatment/retention) $[24,31,39,41,52]$ and participation in subsequent treatment or aftercare [32, 35]. Treatment dropout and relapse after treatment were predicted in at least two studies by the severity of substance use at baseline $[28,38]$.

3.3. Legal Outcomes. The majority of studies found a positive impact of TC treatment on diverse legal outcomes, such as recidivism, rearrest, and reincarceration. Recidivism rates (self-reported criminal involvement) of TC participants after one year are usually around $40 \%-50 \%[19,31]$, as well as rearrest rates $[29,44]$, although one study reported a rearrest rate of only $17 \% 18$ months after the start of TC treatment [42]. Reincarceration rates 12 to 18 months after release are between 30\% and 55\% in most studies, although Sacks and colleagues have reported clearly lower rates (19\% and $9 \%$, resp.) in two studies $[19,36]$. Long-term follow-up measurements of prison TC participants indicate rearrest rates of 63\% after three years [29] and 80\% after five years [44] and reincarceration rates of over $70 \%$ after 5 years $[33,44]$. Again, time to reincarceration was lower in the TC group and treatment completion and/or time in treatment predicted absence of recidivism [28, 31, 33, 36, 42, 49]. Treatment completion was found to be associated with (older) age, single (instead of poly) drug dependence and being on parole [42].

3.4. Long-Term Outcomes and Outcome Predictors. Six controlled studies have investigated the outcomes of TC participants in comparison with controls beyond a period of 12 to 18 months (cf. Table 2). Five of these studies show significantly better legal outcomes in favor of the TC group, while only three studies could demonstrate significantly lower levels of illegal drug use two years after TC treatment. One of these studies [40] found a higher prevalence of alcohol problems among TC participants at the two-year follow-up, when compared with controls who only followed a short detoxification period.

Several studies have identified correlates of relapse and recidivism after TC treatment. Participation in aftercare $[28,35,44]$, posttreatment employment [37], and older age $[28,33]$ were found to be the most common predictors of abstinence and absence of rearrest (cf. Table 1). The effectiveness of completing treatment was shown in several studies, as TC + aftercare completers had better outcomes than aftercare drop-outs, who had in turn better outcomes than TC completers and TC drop-outs $[33,35]$. Martin and colleagues [32] even found no differences between inmates who followed in-prison TC treatment without subsequent aftercare and controls who received usual work release. Relapse to drug use is often associated with reoffending and reincarceration [46].

3.5. Type of Controls and TC Modalities. Eleven studies have compared TC treatment with some form of usual care (e.g., case management, standard treatment, and probation), and five studies compared one type of TC with another form of TC treatment (modified versus standard TCs, or short versus long TC programs). In the latter case, the longest/most comprehensive TC program was regarded as the experimental condition, while the shorter/least intensive program was seen as the control condition. Only three comparisons of longer and shorter TC programs yielded significantly better substance use outcomes at the first follow-up moment $[25,41,42]$, while overall few significant differences were observed in comparison with other TC modalities. Two studies found better employment outcomes compared with lower intensity TC models, and one study found fewer 


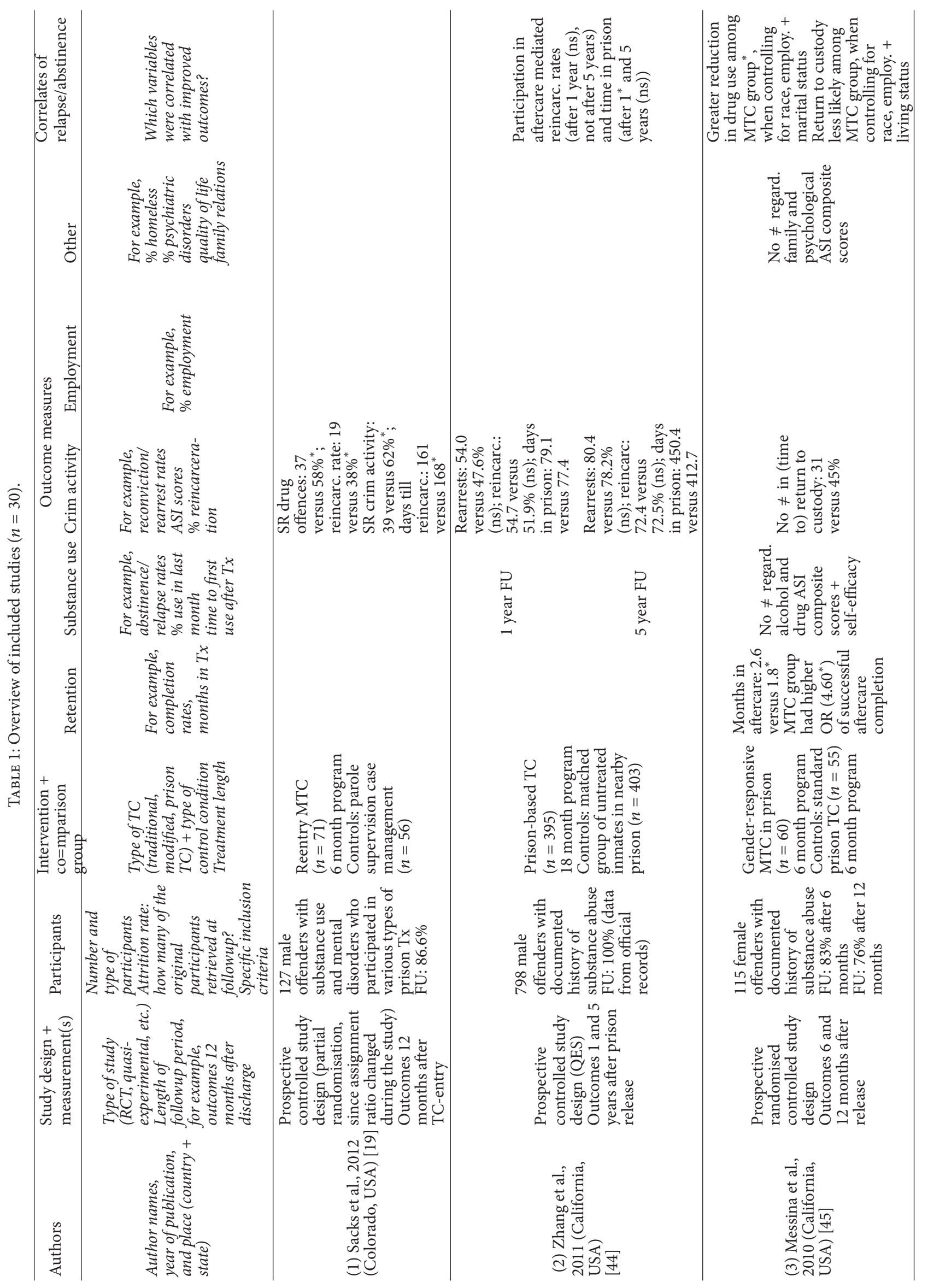




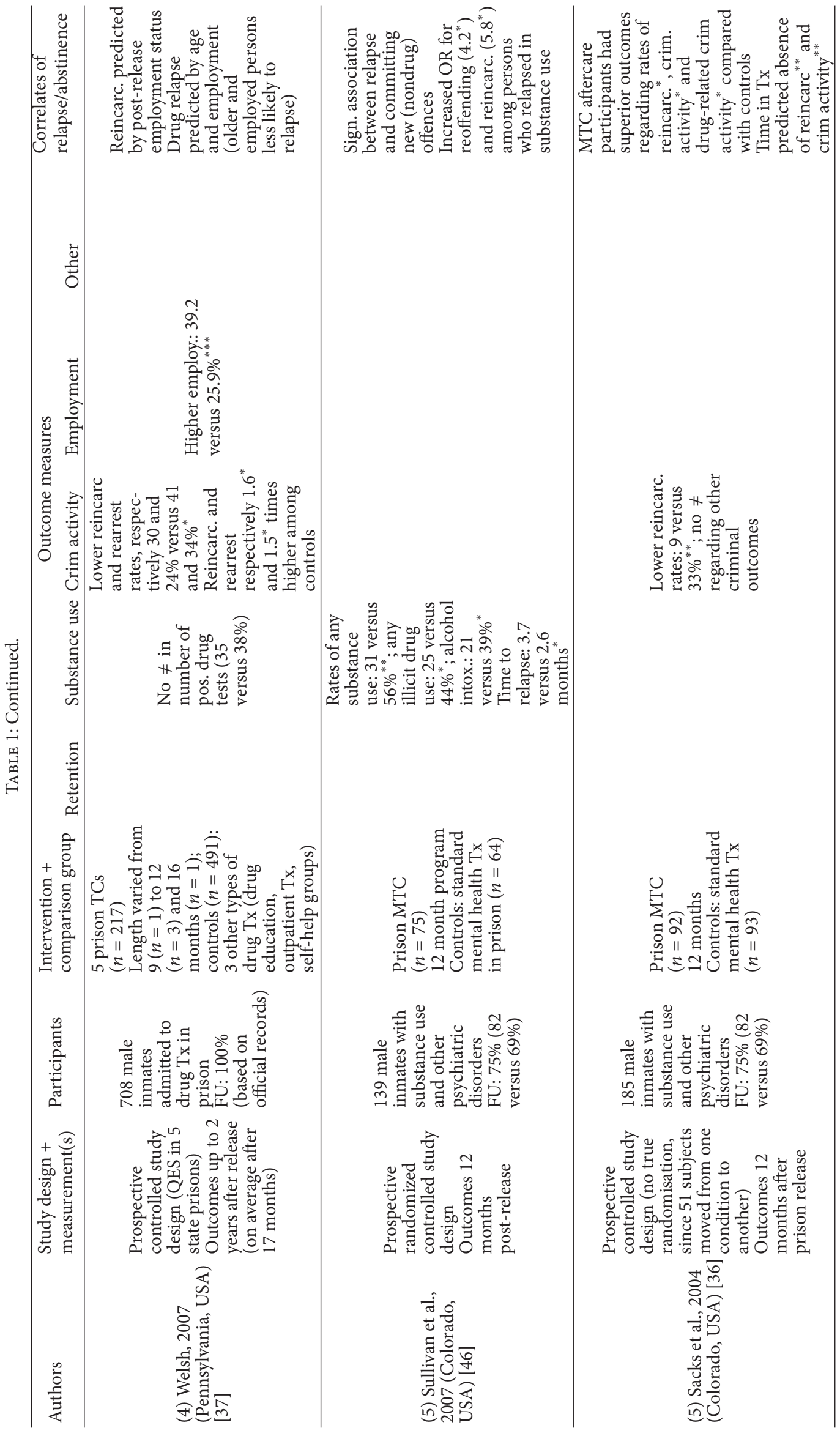




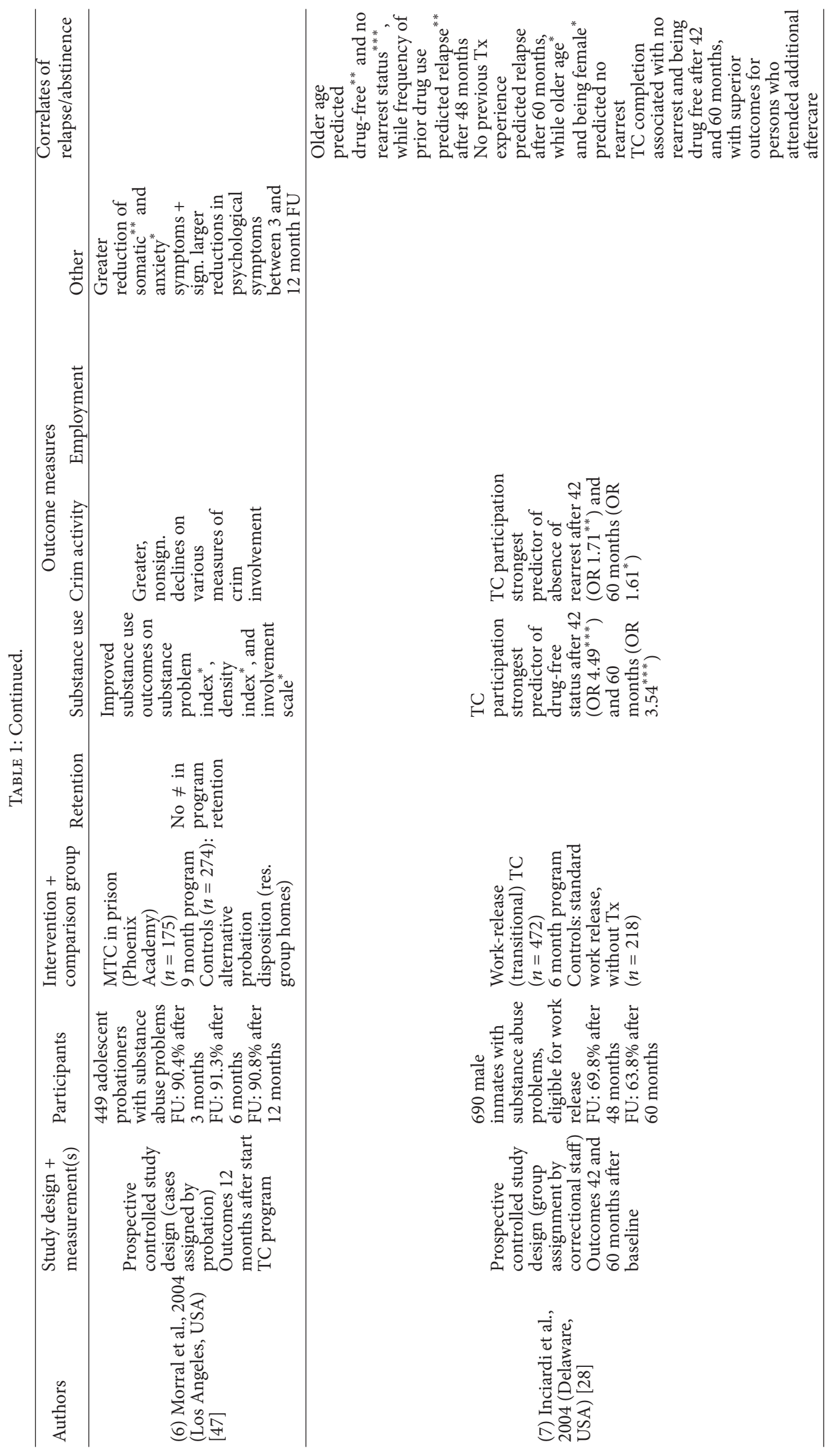




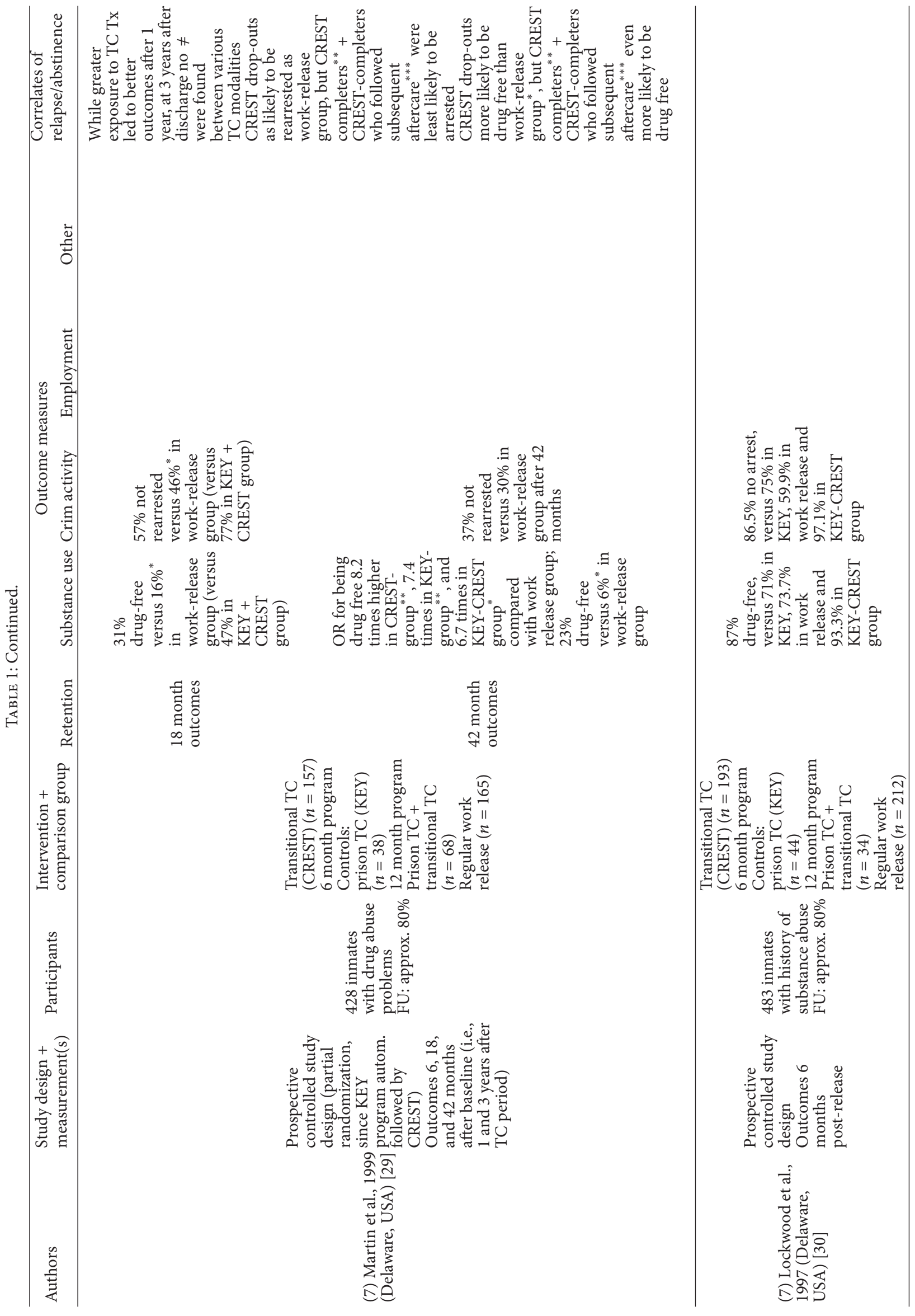




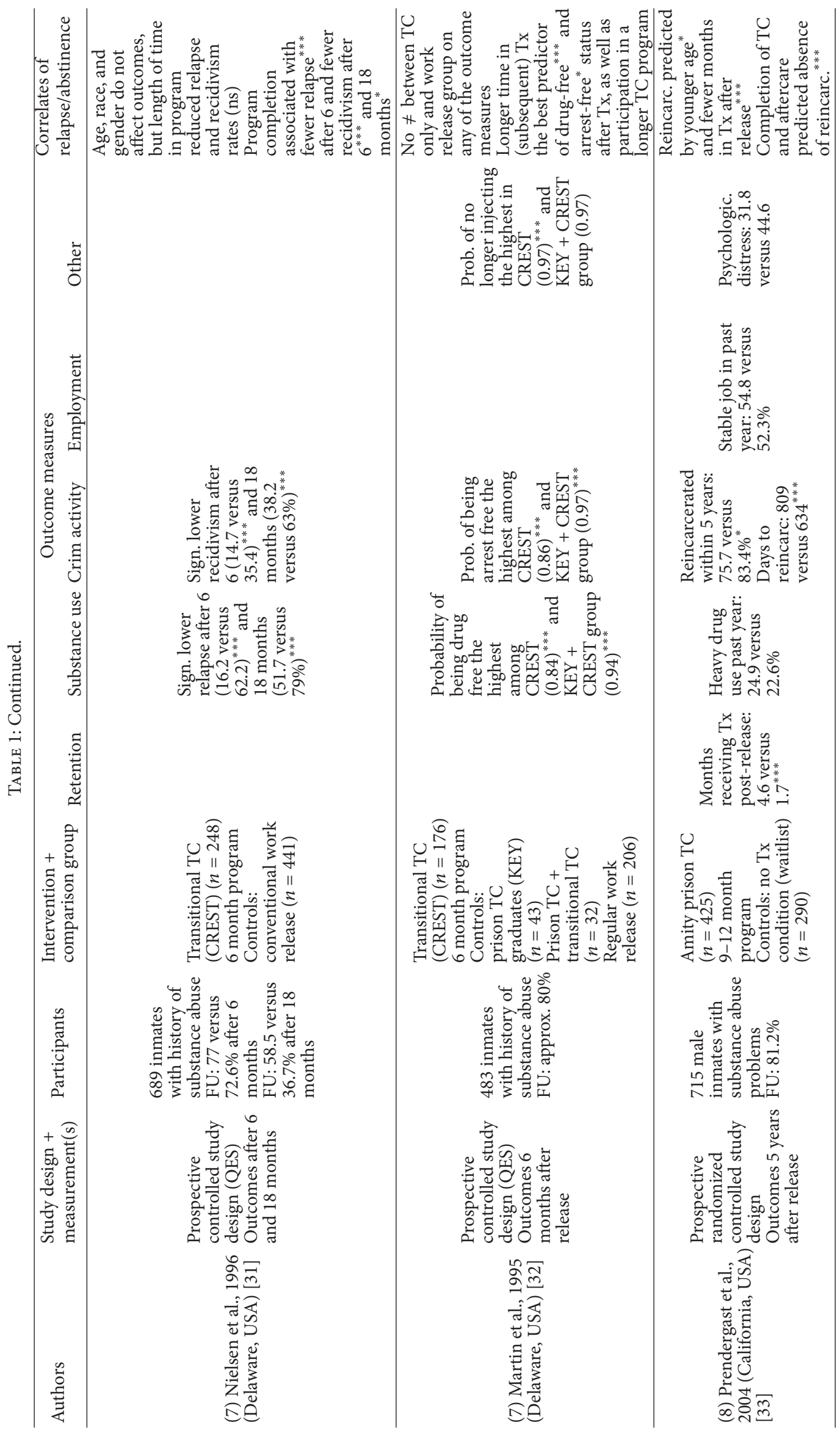




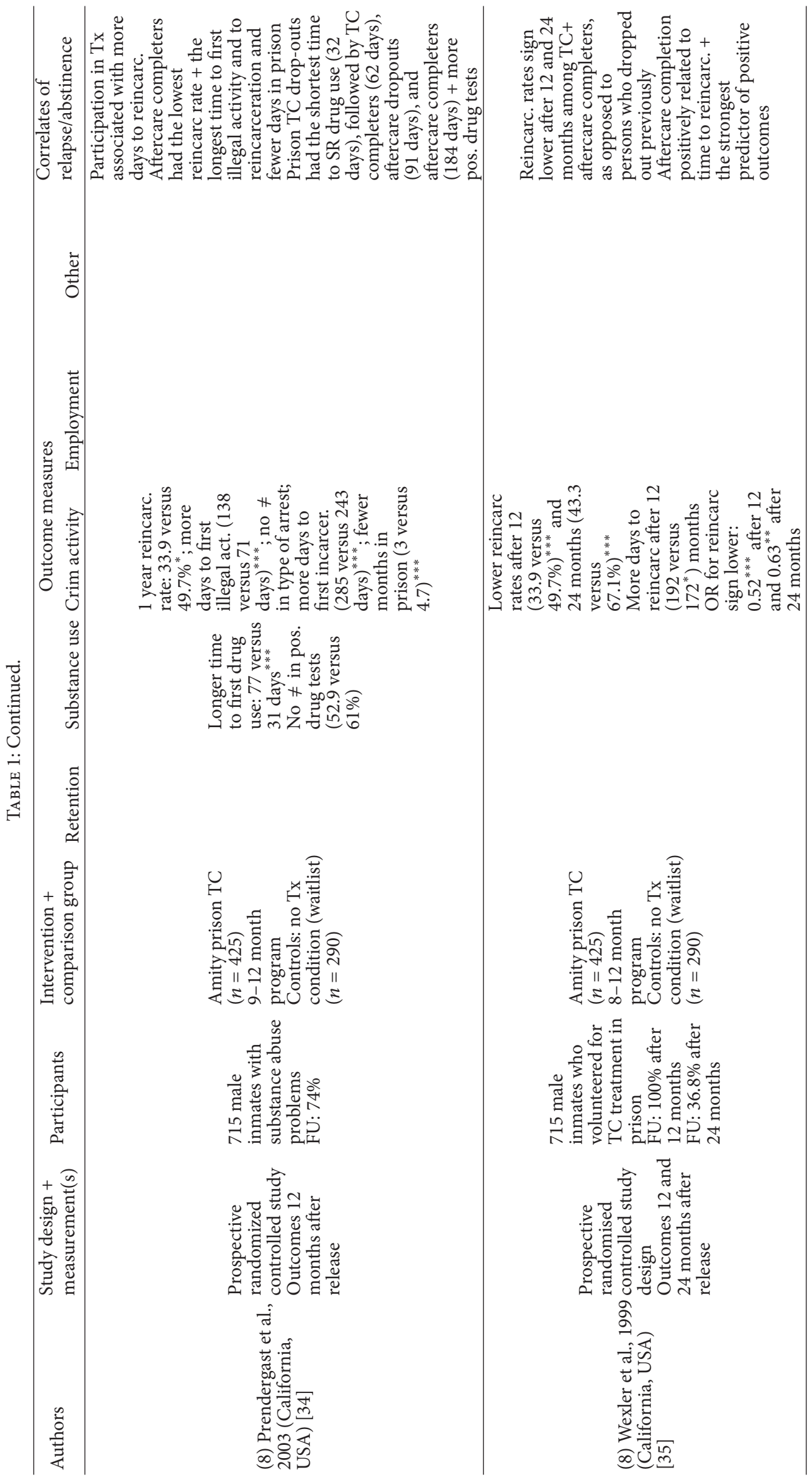



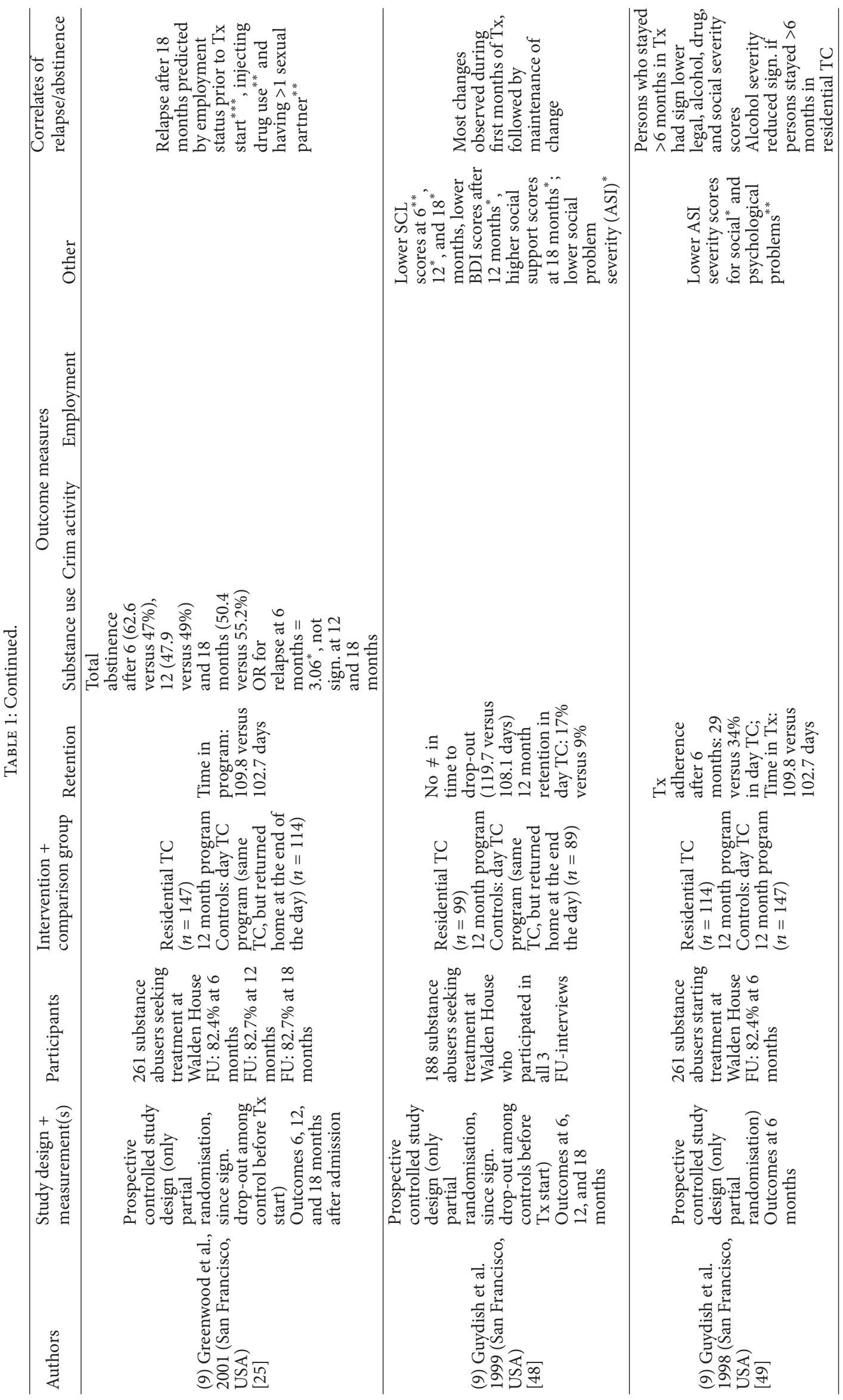

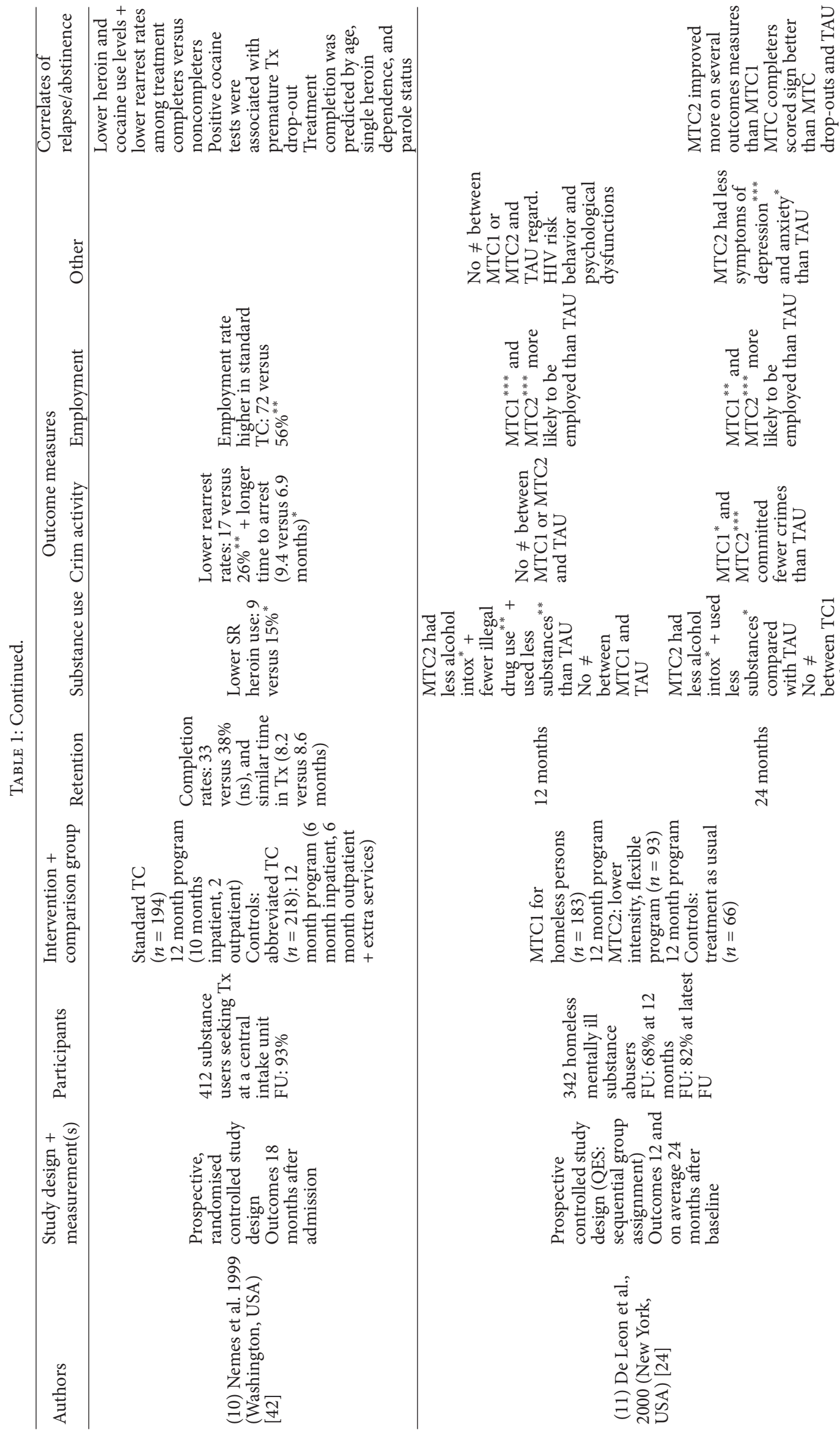

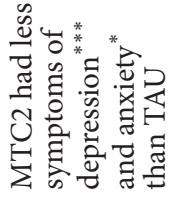
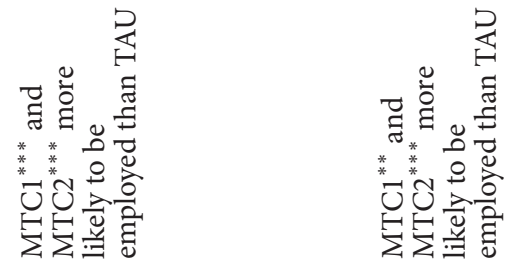

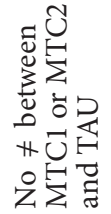

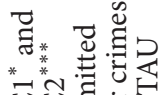

论造总

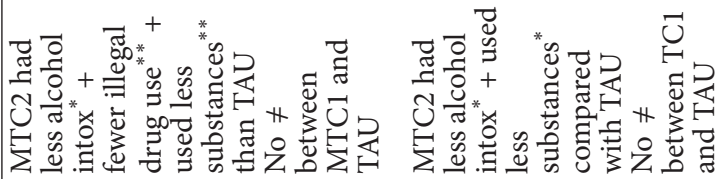

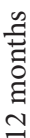
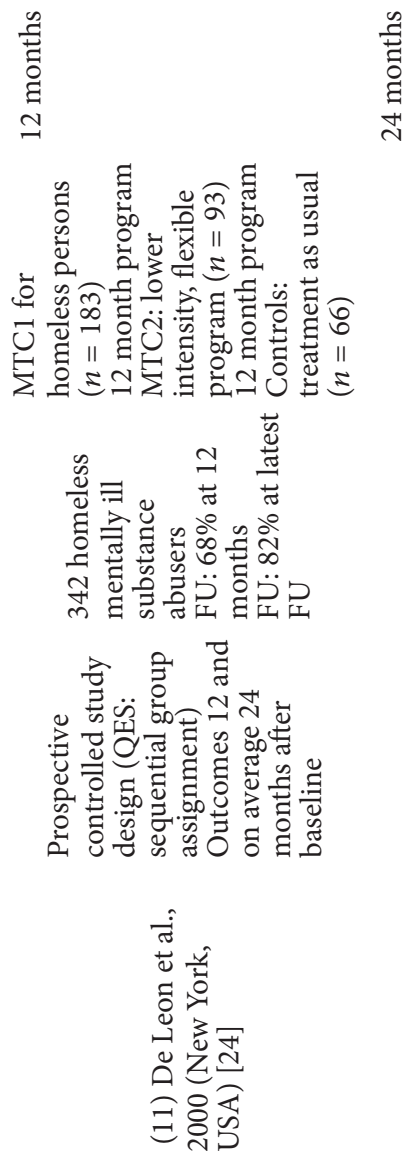


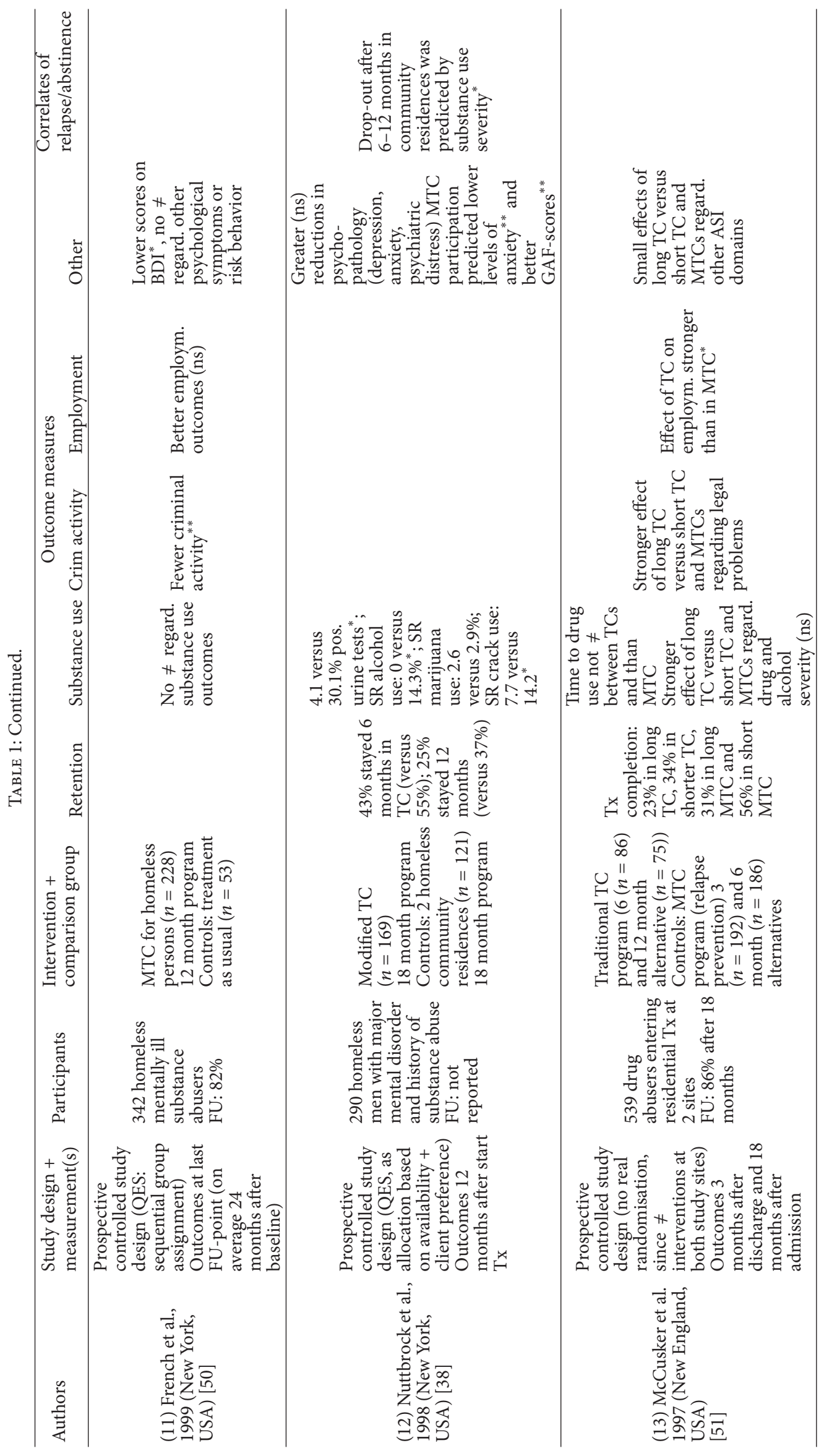




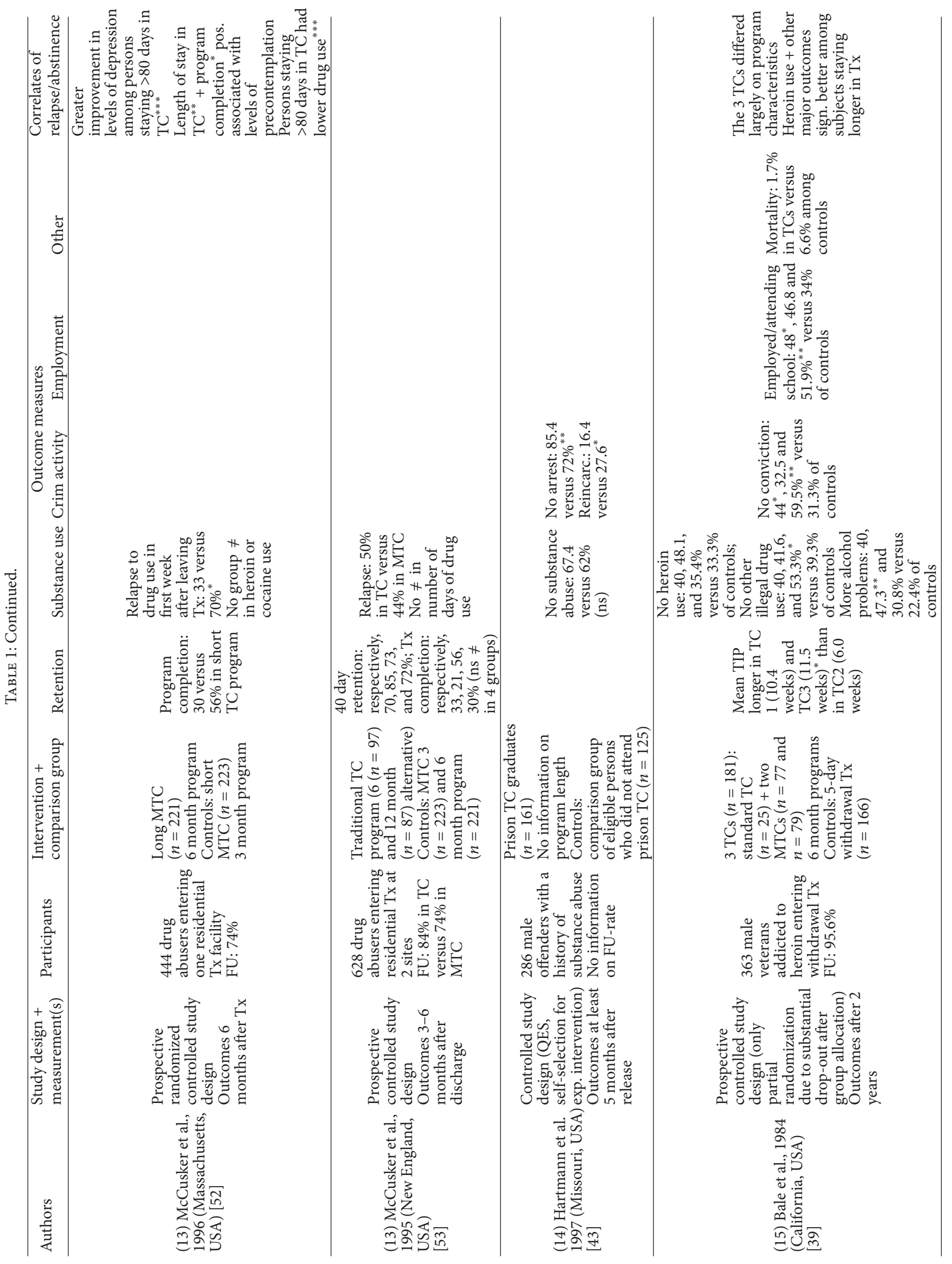




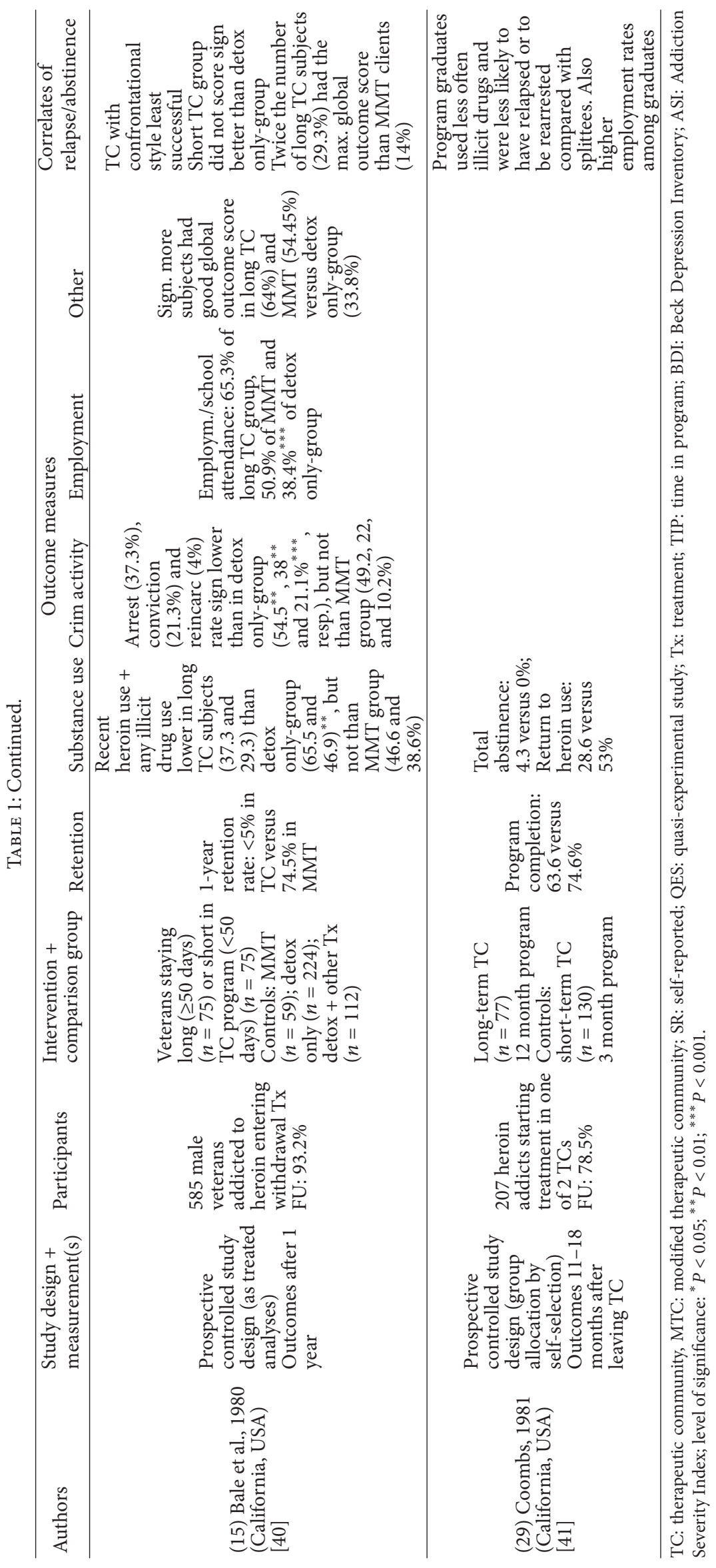




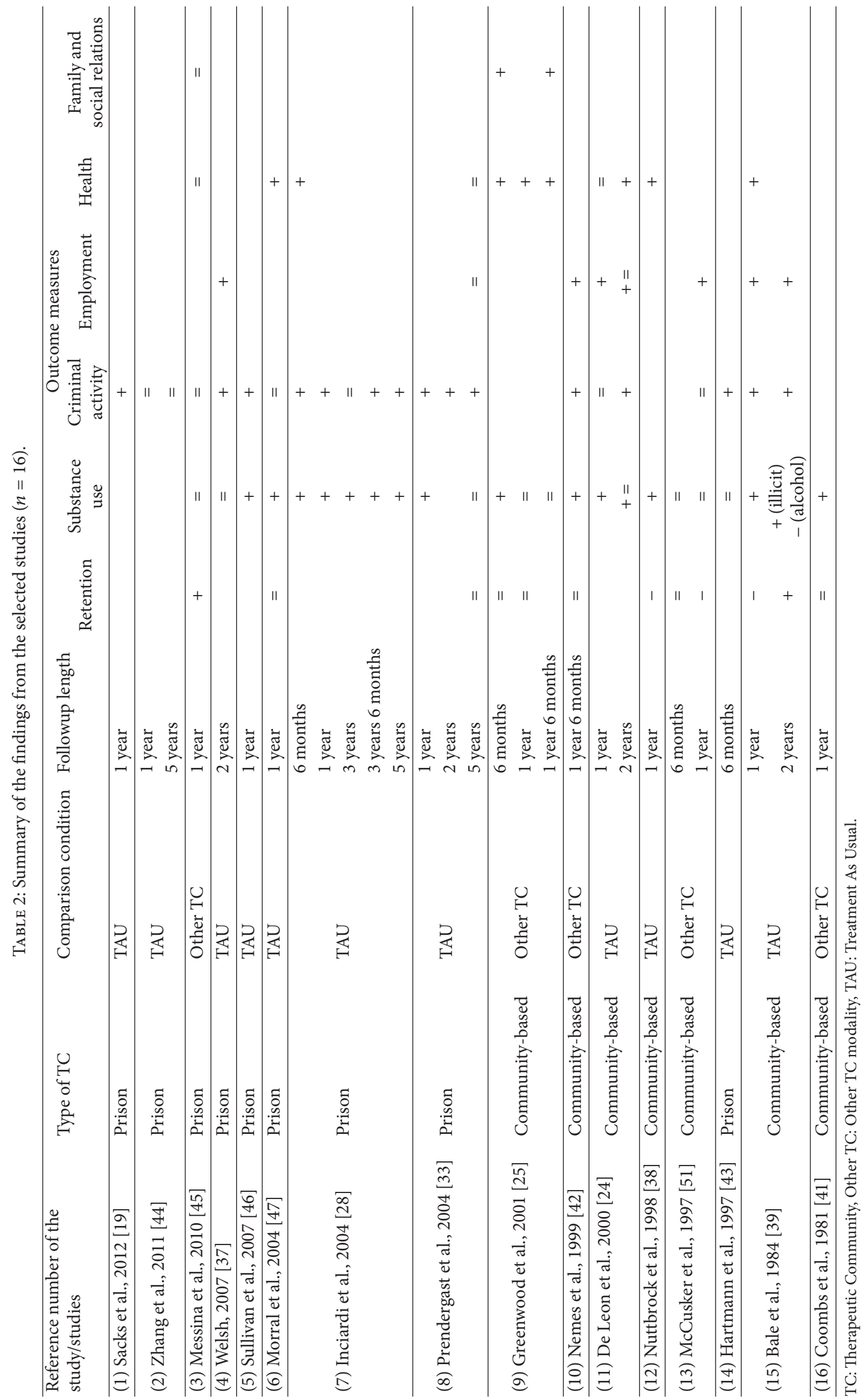


psychological symptoms and relational problems among the higher intensity treatment group. Some studies have included multiple control conditions [29], but usually significant differences were only observed when the most intensive intervention was compared with the least intensive treatment condition.

Most controlled studies of TC effectiveness have focused on TCs in prison settings $(n=9)$ that prepare inmates for reintegration in society, while seven studies concerned TCs in the community. Whereas a substantial number of residents enter community TCs under legal pressure, TC treatment in prison can be regarded as a different context given the compulsory custody and conditional release term and privileges. Substance use outcomes in community TCs were significantly better than those among controls in five (out of 6) studies, while legal outcomes were found to be superior in three (out of 4) studies of community TCs. On the other hand, only in four (out of 7) studies of prison TCs, the experimental group scored significantly better than the control group, and only one study could demonstrate this difference beyond the one-year follow-up assessment [28]. Six (out of 9) prison TC studies found significantly better legal outcomes among TC participants. Three studies could demonstrate these gains after two years, and two studies found these benefits maintained up to five years after prison TC treatment $[28,33]$.

\section{Discussion}

4.1. Main Findings. This narrative review was based on 16 studies that have evaluated the effectiveness of TCs as compared with other viable interventions regarding various indicators related with recovery: substance use, criminal involvement, employment, psychological well being, and family and social relations. Based on the study findings, we can conclude that there is some evidence for the effectiveness of therapeutic community treatment. Almost two out of three studies have shown significantly better substance use and legal outcomes at the first follow-up moment after treatment among persons who stayed in a TC as compared with controls. Five studies found superior employment outcomes among TC participants, while another five studies showed significantly fewer psychological problems in the experimental group. Only four studies have reported significantly better differential outcomes in at least three outcome categories. This does not mean that TC participants do not improve equally on all life domains, but these outcomes often remained unreported or the observed progress did not differ significantly from that among the control group. Several reviews $[22,26,27,54]$ have addressed the question whether TCs generate better outcomes than other interventions, often leading to conflicting and not really convincing conclusions. Although several studies included in this paper showed improved differential outcomes [28, 33, 38, 39, 42, 50], these findings were observed among varying populations in diverse settings, and few studies have succeeded to replicate the findings from other studies in exactly the same conditions. Moreover, some studies [25, 42, 45] have compared modified TCs with standard TCs that were not specifically adapted to address the needs of special target groups. In general, such comparisons of one type of (modified) TC with a less intensive (standard) TC model did not demonstrate much between group differences, given the strong similarities between both treatment conditions. Consequently, the main question is not whether one type of TC is better than another intervention/type of TC, but rather which persons benefit most from (what type of) TC treatment at what point in the recovery process [22]. Also, uncontrolled treatment outcome studies have repeatedly shown fairly similar effects of various types of residential treatment $[55,56]$ and when compared with outpatient methadone treatment $[40,57,58]$, demonstrating that-from a longitudinal perspective-no single intervention is superior to another. Not the differential effectiveness of TCs, but rather individuals' assets and community resources and their personal needs and goals will determine whether TC treatment is indicated on the road to recovery.

4.2. Towards a Recovery Perspective on TC Treatment. While looking beyond abstinence and desistance is warranted from a recovery perspective [8], six of the selected controlled studies did not report other than substance use and legal outcomes. Stable recovery in opiate addicts has been primarily associated with social participation and having meaningful activities and purposes in life, rather than with drug abstinence or controlled drug use [59]. Focus groups with drug users regarding their perceived quality of life revealed few specific but mostly generic aspects of QoL like well being, social inclusion, and human rights [60]. Still, a predominant focus on objective socially desirable outcome measures (e.g., work, alcohol and drug use, and recidivism) prevails in addiction research, while more subjective outcome indicators like emotional well being, quality of life, or job satisfaction have largely been disregarded [61]. Such a broad perspective is also needed in TC research, as it allows a more accurate evaluation of individuals' personal growth and well being after TC treatment. Up to now, recovery has primarily been measured based on abstinence rates after TC treatment, while abstinence is not a synonym of nor a prerequisite for recovery [8]. Total abstinence-as required during and expected after TC treatment-appears not to be self-evident, not even after a lengthy treatment episode in a TC and subsequent continuing care. TC participants typically improve on most life domains during the first months of treatment and are usually able to maintain this status until they leave treatment $[26,48]$. However, once individuals leave the TC, success rates tend to drop quickly, especially during the first month(s) after treatment. A recent review of longitudinal (mostly uncontrolled) TC studies showed that $21 \%$ to $100 \%$ relapsed into drug use six months to six years after leaving treatment [26]. We found substantial relapse rates $(25 \%-70 \%) 12$ to 18 months after leaving treatment, which indicate that $30 \%$ to $75 \%$ of the studied TC sample did not relapse within one year after TC treatment. Although the definition of "relapse" varied largely between studies (e.g., any substance use, illicit drug use, regular use, and last month use), relapse can be addressed in at least two different ways, depending whether one starts from an acute 
or a continuing care perspective. The former approach sees relapse as a failure as treated individuals did not succeed to abstain from drug use after intensive treatment. The latter perspective acknowledges the chronic relapsing nature of drug addiction and assumes that relapse is part and parcel of the recovery process and should rather be considered as a learning moment to keep the precarious balance between abstinence and relapse [62]. Factors that may contribute to recovery are longer length of stay in the TC (retention) and participation in subsequent aftercare, since both variables have been consistently identified as predictors of improved substance use outcomes [23, 26]. Surprisingly, treatment completion was not found to be a predictor of abstinence, but it was associated with reduced recidivism rates in several studies of prison TCs $[33,36]$.

Treatment in TCs for addictions takes time, usually around 6 to 12 months, which heightens the possibility that residents leave prematurely [27]. Retention in (longer term) TCs is typically lower than in shorter term programs $[42,51$, 55], but in general TC residents who stayed longer in treatment had significantly better outcomes than persons who dropped out early. This has led to concerns with enhancing retention through the involvement of the family and social network and the use of senior staff [63] and with promoting initial engagement through motivational interviewing, contingency management, and induction interventions [64-66]. An alternative promising way of looking at retention may be to see it as the sum of treatment episodes in different services and the accumulation of associated treatment experiences instead of defining retention as a single uninterrupted stay in one treatment program [67]. Reentry in the community appears to be a critical point after TC treatment, if not prepared adequately (e.g., by providing aftercare) or if drug users go back to their old neighborhoods [68]. Some type of continuing support is warranted after TC treatment not only to prevent relapse, but also to link with employment/training and to engage in community-based activities. Moreover, treatment discharge should be dealt with in a flexible and individualized way, since some persons will need to be further supported or to reenter the community if they are doing poorly.

The recovery movement starts from a longitudinal approach to addiction and other mental health problems [69], but few controlled studies have assessed TC outcomes beyond a two-year follow-up period. Available studies suggest that-despite a fading effect of TC treatment over time-recidivism rates continued to be significantly better than these of controls in three studies of prison TCs [28, $33,37]$, while findings regarding substance use outcomes indicated fewer between group differences. The three-year follow-up outcomes of the Delaware prison study showed a 94\% relapse rate among the usual care group (traditional work release) compared with a $77 \%$ relapse rate in the prison aftercare TC group [29]. These figures do not only illustrate the relapsing nature of addiction problems, but also point at the relatively poor effectiveness of treatment programs. Although robust study designs including substantial followup periods that are able to retain most respondents in the analyses are needed, one may not overestimate the lasting effects of one single (prolonged) treatment episode. Recovery is considered to be a lengthy process, and continuing care is needed to maintain recovery that has been initiated during, for example, TC treatment. Some studies have shown that the provision of aftercare was as or even more effective than initial TC treatment [29, 70], and the combination of TC treatment and subsequent aftercare has generated the best results $[33,71]$.

Finally, the study findings show that TC treatment has generated beneficial outcomes in diverse treatment settings and may have particularly strong effects among severely addicted individuals like incarcerated, homeless, and mentally ill drug addicts $[22,36,37,46]$. Therefore, treatment in TCs should be considered as a specific intervention, reserved for drug addicts with multiple and severe problems. Although outpatient methadone maintenance therapy is the mainstream addiction treatment worldwide, therapeutic communities for addictions can be regarded as a valuable alternative for persons who do not do well in outpatient treatment due to the lack of structure and supports in the community and the fact that they live in neighborhoods that are pervasively affected by drug abuse [68]. TCs can be supportive places where clients can learn some of the internal control and refusal skills conducive to stable recovery. Motivation, social support and coping with stress without using substances appear to be key factors in successful recovery [72].

4.3. Limitations of the Paper. First, most selected studies were published in peer reviewed journals. Although the restriction of peer-review guarantees some form of quality control, it may have induced a selection bias as the likelihood of retrieving non-English language articles was limited in this way. Only results that were reported in the published papers could be included, while it was often unclear whether the nonreporting of some specific outcomes (e.g., recidivism, alcohol use) meant that this information was not collected, not analyzed, or did not yield significant findings. Second, substantial heterogeneity has been observed between the included studies, not only regarding program and setting characteristics, but also regarding sample characteristics and outcome measures. Despite the common "community as method" principle [18], TCs for addictions consist of various practices and programs with varying treatment length. Standard and modified TC programs have been evaluated in this paper, as well as TCs in prison settings and aftercare TCs. This heterogeneity should be taken into account when interpreting the study outcomes. Although the underlying elements may be fairly similar across TC programs, the dosage of the program and fidelity to the concept may have varied considerably [22, 27]. Also, types of controls varied across studies from waitlist controls to interventions that differed only slightly from the experimental group (e.g., residential/longer versus day/shorter TC programs). Another limitation is the use of varying outcome measures and instruments across studies, which further hampers the replication and generalization of the findings. Third, this systematic review was not restricted to randomized trials, although the Cochrane collaboration and other proponents 
of the evidence-based paradigm regard this type of study design as the gold standard for the evaluation of evidence of effectiveness [73]. Given the difficulties to apply this design to long-term and comprehensive multi-interventions like TCs and the low number of randomized controlled trials on the effectiveness of TCs, a comprehensive review of randomized and nonrandomized controlled studies was deemed to be of surplus value in comparison with available reviews, still generating an acceptable level of evidence [68]. Treatment drop-outs may further compromise the validity of the reported results. Several studies only included substance users who stayed for a substantial period in the TC or who completed treatment but made no intent-to-treat analysis of everyone who started TC treatment (cf. Table 1). Finally, this is a narrative review of controlled studies that does not allow to weigh the findings from different studies or to estimate effect sizes. A meta-analysis was not possible at this point, given the substantial heterogeneity between programs and the diverse outcome categories and measures that were reported in the selected studies.

\section{Conclusion}

Therapeutic communities for addictions can be regarded as recovery-oriented programs that produce change regarding substance use, legal, employment, and psychological wellbeing outcomes among drug addicts with severe and multiple problems. Despite various methodological constraints, TCs appeared to generate significantly better outcomes in comparison with other viable interventions in two out of three studies. TC programs have usually been evaluated from an acute care perspective with a primary focus on abstinence and recidivism, while a continuing care approach including multiple and more subjective outcome indicators is necessary from a recovery perspective. If residents stay long enough in treatment and participate in subsequent aftercare, TCs can play an important role on the way to recovery. Abstinence may be just one resource to promote employment or enhance personal well being which can in turn contribute to recovering addicts' participation in community-based activities and their social inclusion.

\section{Acknowledgments}

This study was supported by the European Monitoring Centre for Drugs and Drug Addiction (EMCDDA) (Contract code: CT.11.IBS.057). The authors would like to thank Dr. Teodora Groshkova for her support with this comprehensive review of the outcome literature on TCs for addictions. They are further grateful to Ilse Goethals and Mieke Autrique for their preparatory work for this literature review.

\section{References}

[1] R. K. Brooner, V. L. King, M. Kidorf, C. W. Schmidt Jr., and G. E. Bigelow, "Psychiatric and substance use comorbidity among treatment-seeking opioid abusers," Archives of General Psychiatry, vol. 54, no. 1, pp. 71-80, 1997.
[2] J. Storbjörk, The social ecology of alcohol and drug treatment [Ph.D. thesis], SoRAD, Stockholm University, Stockholm, Sweden, 2006.

[3] R. West, Theory of Addiction, Blackwell Publishing, Malden, Mass, USA, 2006.

[4] A. T. McLellan, D. C. Lewis, C. P. O'Brien, and H. D. Kleber, "Drug dependence, a chronic medical illness implications for treatment, insurance, and outcomes evaluation," Journal of the American Medical Association, vol. 284, no. 13, pp. 1689-1695, 2000.

[5] A. T. McLellan, "Have we evaluated addiction treatment correctly? Implications from a chronic care perspective," Addiction, vol. 97, no. 3, pp. 249-252, 2002.

[6] A. T. McLellan, J. R. McKay, R. Forman, J. Cacciola, and J. Kemp, "Reconsidering the evaluation of addiction treatment: from retrospective follow-up to concurrent recovery monitoring," Addiction, vol. 100, no. 4, pp. 447-458, 2005.

[7] W. White, Recovery Management and Recovery-Oriented Systems of Care: Scientific Rationale and Promising Practices, Northeast Addiction Technology Transfer Center, Great Lakes Addiction Technology Transfer Center and Philadelphia Department of Behavioral Health \& Mental Retardation Services, Pittsburgh, Pa, USA, 2008.

[8] D. Best, Addiction Recovery. A Movement For Social Change and Personal Growth in the UK, Pavillion Publishing, Brighton, UK, 2012.

[9] A. B. Laudet and W. White, "What are your priorities right now? Identifying service needs across recovery stages to inform service development," Journal of Substance Abuse Treatment, vol. 38, no. 1, pp. 51-59, 2010.

[10] W. White, "Toward a new recovery advocacy movement," in Proceedings of the Recovery Community Support Program Conference "Working Together for Recovery", Johnson Institute and Faces and Voices of Recovery, Arlington, Va, USA, April 2000.

[11] Y. -I. Hser and M. D. Anglin, "Addiction treatment and recovery careers," in Addiction Recovery Management: Theory, Research and Practice, J. F. Kelly and W. L. White, Eds., pp. 9-31, Springer Science, New York, NY, USA, 2011.

[12] I. Goethals, V. Soyez, G. Melnick, G. D. Leon, and E. Broekaert, "Essential elements of treatment: a comparative study between European and American therapeutic communities for addiction," Substance Use and Misuse, vol. 46, no. 8, pp. 1023-1031, 2011.

[13] E. Broekaert, M. Kooyman, and D. J. Ottenberg, "The "new" drug-free therapeutic community: challenging encounter of classic and open therapeutic communities," Journal of Substance Abuse Treatment, vol. 15, no. 6, pp. 595-597, 1998.

[14] W. Vanderplasschen, S. Vandevelde, and E. Broekaert, Therapeutic Communities For Addictions in Europe. Available Evidence, Current Practices and Future Challenges For RecoveryOriented Treatment in Therapeutic Communities For Drug Addicts (EMCDDA Insights Publication), European Monitoring Centre for Drugs and Drug Addiction (EMCDDA), Lisbon, Portugal.

[15] P. Degkwitz and H. Zurhold, "Overview of types, characteristics, level of provision and utilisation of drug treatment services in the European member states and Norway," in Quality of Treatment Services in Europe-Drug Treatment Situation and Exchange of Good Practice, European Commission Health \& Consumer Protection Directorate-General, 
Directorate C-Public Health and Risk Assessment, Brussels, Belgium, 2008.

[16] Substance Abuse Mental Health Services Administration (SAMHSA), Alcohol and Drug Services Study (ADSS): The National Substance Abuse Treatment System: Facilities, Clients, Services, and Staffing, Office of Applied Studies, Rockville, Md, USA, 2003.

[17] European Monitoring Centre for Drugs and Drug Addiction (EMCDDA), Annual Report on the State of the Drugs Problem in Europe 2010, European Monitoring Centre for Drugs and Drug Addiction (EMCDDA), Lisbon, Portugal, 2010.

[18] G. De Leon, Community As Method: Therapeutic Community For Special Populations and Special Settings, Greenwood Publishing Group, Westport, Conn, USA, 1997.

[19] S. Sacks, M. Chaple, J. Y. Sacks, K. McKendrick, and M. Cleland, "Randomized trial of a re-entry modified therapeutic community for offenders with co-occurring disorders: crime outcomes," Journal of Substance Abuse Treatment, vol. 42, no. 3, pp. 247-259, 2012.

[20] G. De Leon, "Integrative recovery: a stage paradigm," Substance Abuse, vol. 17, no. 1, pp. 51-63, 1996.

[21] E. Broekaert, S. Vandevelde, V. Soyez, R. Yates, and A. Slater, "The third generation of therapeutic communities: the early development of the TC for addictions in Europe," European Addiction Research, vol. 12, no. 1, pp. 1-11, 2006.

[22] G. De Leon, "Is the therapeutic community an evidence-based treatment? What the evidence says," International Journal of Therapeutic Communities, vol. 31, no. 2, pp. 104-128, 2010.

[23] L. A. Smith, S. Gates, and D. Foxcroft, "Therapeutic communities for substance related disorder," Cochrane Database of Systematic Reviews, no. 1, article CD005338, 2006.

[24] G. De Leon, S. Sacks, G. Staines, and K. McKendrick, "Modified therapeutic community for homeless mentally ill chemical abusers: treatment outcomes," American Journal of Drug and Alcohol Abuse, vol. 26, no. 3, pp. 461-480, 2000.

[25] G. L. Greenwood, W. J. Woods, J. Guydish, and E. Bein, "Relapse outcomes in a randomized trial of residential and day drug abuse treatment," Journal of Substance Abuse Treatment, vol. 20, no. 1, pp. 15-23, 2001.

[26] M. Malivert, M. Fatséas, C. Denis, E. Langlois, and M. Auriacombe, "Effectiveness of therapeutic communities: a systematic review," European Addiction Research, vol. 18, no. 1, pp. 1-11, 2012.

[27] J. Lees, N. Manning, and B. Rawlings, "A culture of enquiry: research evidence and the therapeutic community," Psychiatric Quarterly, vol. 75, no. 3, pp. 279-294, 2004.

[28] J. A. Inciardi, S. S. Martin, and C. A. Butzin, "Five-year outcomes of therapeutic community treatment of drug-involved offenders after release from prison," Crime and Delinquency, vol. 50, no. 1, pp. 88-107, 2004.

[29] S. S. Martin, C. A. Butzin, C. A. Saum, and J. A. Inciardi, "Threeyear outcomes of therapeutic community treatment for druginvolved offenders in delaware: from prison to work release to aftercare," Prison Journal, vol. 79, no. 3, pp. 294-320, 1999.

[30] D. Lockwood, J. A. Inciardi, C. A. Butzin, and R. M. Hooper, "The therapeutic community continuum in corrections," in Community As Method. Therapeutic Communities For Special Populations and Special Settings, G. De Leon, Ed., pp. 87-96, Praeger, Westport, Conn, USA, 1997.

[31] A. L. Nielsen, F. R. Scarpitti, and J. A. Inciardi, "Integrating the therapeutic community and work release for drug-involved offenders: the CREST program," Journal of Substance Abuse Treatment, vol. 13, no. 4, pp. 349-358, 1996.

[32] S. S. Martin, C. A. Butzin, and J. A. Inciardi, "Assessment of a multistage therapeutic community for drug-involved offenders," Journal of Psychoactive Drugs, vol. 27, no. 1, pp. 109-116, 1995.

[33] M. L. Prendergast, E. A. Hall, H. K. Wexler, G. Melnick, and Y. Cao, "Amity prison-based therapeutic community: 5-Year outcomes," Prison Journal, vol. 84, no. 1, pp. 36-60, 2004.

[34] M. L. Prendergast, E. A. Hall, and H. K. Wexler, "Multiple measures of outcome in assessing a prison-based drug treatment program," Journal of Offender Rehabilitation, vol. 37, no. 3-4, pp. 65-94, 2003.

[35] H. K. Wexler, G. De Leon, G. Thomas, D. Kressel, and J. Peters, "The amity prison TC evaluation: reincarceration outcomes," Criminal Justice and Behavior, vol. 26, no. 2, pp. 147-167, 1999.

[36] S. Sacks, J. Y. Sacks, K. McKendrick, S. Banks, and J. Stommel, "Modified TC for MICA offenders: crime outcomes," Behavioral Sciences and the Law, vol. 22, no. 4, pp. 477-501, 2004.

[37] W. N. Welsh, "A multisite evaluation of prison-based therapeutic community drug treatment," Criminal Justice and Behavior, vol. 34, no. 11, pp. 1481-1498, 2007.

[38] L. A. Nuttbrock, M. Rahav, J. J. Rivera, D. S. Ng-Mak, and B. G. Link, "Outcomes of homeless mentally ill chemical abusers in community residences and a therapeutic community," Psychiatric Services, vol. 49, no. 1, pp. 68-76, 1998.

[39] R. N. Bale, V. P. Zarcone, W. W. Van Stone, J. M. Kuldau, T. M. J. Engelsing, and R. M. Elashoff, "Three therapeutic communities. A prospective controlled study of narcotic addiction treatment: process and two-year follow-up results," Archives of General Psychiatry, vol. 41, no. 2, pp. 185-191, 1984.

[40] R. N. Bale, W. W. Van Stone, J. M. Kuldau, T. M. Engelsing, R. M. Elashoff, and V. P. Zarcone, "Therapeutic communities versus methadone maintenance: a prospective controlled study of narcotic addiction treatment: design and one-year followup," Archives of General Psychiatry, vol. 37, no. 2, pp. 179-193, 1980.

[41] R. H. Coombs, "Back on the streets: therapeutic communities' impact upon drug users," American Journal of Drug and Alcohol Abuse, vol. 8, no. 2, pp. 185-201, 1981.

[42] S. Nemes, E. D. Wish, and N. Messina, "Comparing the impact of standard and abbreviated treatment in a therapeutic community-findings from the district of Columbia treatment initiative experiment," Journal of Substance Abuse Treatment, vol. 17, no. 4, pp. 339-347, 1999.

[43] D. J. Hartmann, J. L. Wolk, J. S. Johnston, and C. J. Colyer, "Recidivism and substance abuse outcomes in a prison-based therapeutic community," Federal Probation, vol. 61, no. 4, pp. 18-25, 1997.

[44] S. X. Zhang, R. E. L. Roberts, and K. E. McCollister, "Therapeutic community in a california prison: treatment outcomes after 5 years," Crime and Delinquency, vol. 57, no. 1, pp. 82-101, 2011.

[45] N. Messina, C. E. Grella, J. Cartier, and S. Torres, "A randomized experimental study of gender-responsive substance abuse treatment for women in prison," Journal of Substance Abuse Treatment, vol. 38, no. 2, pp. 97-107, 2010.

[46] C. J. Sullivan, K. McKendrick, S. Sacks, and S. Banks, "Modified therapeutic community treatment for offenders with mica disorders: substance use outcomes," American Journal of Drug and Alcohol Abuse, vol. 33, no. 6, pp. 823-832, 2007. 
[47] A. R. Morral, D. F. McCaffrey, and G. Ridgeway, "Effectiveness of community-based treatment for substance-abusing adolescents: 12-Month outcomes of youths entering Phoenix Academy or alternative probation dispositions," Psychology of Addictive Behaviors, vol. 18, no. 3, pp. 257-268, 2004.

[48] J. Guydish, J. L. Sorensen, M. Chan, A. Bostrom, D. Werdegar, and A. Acampora, "A randomized trial comparing day and residential drug abuse treatment: 18-month outcomes," Journal of Consulting and Clinical Psychology, vol. 67, no. 3, pp. 428-434, 1999.

[49] J. Guydish, D. Werdegar, J. L. Sorensen, W. Clark, and A. Acampora, "Drug abuse day treatment: a randomized clinical trial comparing day and residential treatment programs," Journal of Consulting and Clinical Psychology, vol. 66, no. 2, pp. 280-289, 1998.

[50] M. T. French, S. Sacks, G. De Leon, G. Staines, and K. McKendrick, "Modified therapeutic community for mentally ill chemical abusers: outcomes and costs," Evaluation and the Health Professions, vol. 22, no. 1, pp. 60-85, 1999.

[51] J. McCusker, C. Bigelow, R. Frost et al., "The effects of planned duration of residential drug abuse treatment on recovery and HIV risk behavior," American Journal of Public Health, vol. 87, no. 10, pp. 1637-1644, 1997.

[52] J. Mccusker, A. Stoddard, R. Frost, and M. Zorn, "Planned versus actual duration of drug abuse treatment: reconciling observational and experimental evidence," Journal of Nervous and Mental Disease, vol. 184, no. 8, pp. 482-489, 1996.

[53] J. McCusker, M. Vickers-Lahti, A. Stoddard et al., "The effectiveness of alternative planned durations of residential drug abuse treatment," American Journal of Public Health, vol. 85, no. 10, pp. 1426-1429, 1995.

[54] S. Sacks and J. Y. Sacks, "Research on the effectiveness of the modified therapeutic community for persons with cooccurring substance use and mental disorders," International Journal of Therapeutic Communities, vol. 31, no. 2, pp. 176-211, 2010.

[55] R. H. Moos, B. S. Moos, and J. M. Andrassy, "Outcomes of four treatment approaches in community residential programs for patients with substance use disorders," Psychiatric Services, vol. 50, no. 12, pp. 1577-1583, 1999.

[56] M. L. Prendergast, D. Podus, E. Chang, and D. Urada, "The effectiveness of drug abuse treatment: a meta-analysis of comparison group studies," Drug and Alcohol Dependence, vol. 67, no. 1, pp. 53-72, 2002.

[57] D. D. Simpson, G. W. Joe, and B. S. Brown, "Treatment retention and follow-up outcomes in the drug abuse treatment outcome study (DATOS)," Psychology of Addictive Behaviors, vol. 11, no. 4, pp. 294-307, 1997.

[58] M. Gossop, J. Marsden, D. Stewart, and T. Kidd, “The National Treatment Outcome Research Study (NTORS): 4-5 year followup results," Addiction, vol. 98, no. 3, pp. 291-303, 2003.

[59] J. De Maeyer, W. Vanderplasschen, L. Camfield, S. Vanheule, B. Sabbe, and E. Broekaert, "A good quality of life under the influence of methadone: a qualitative study among opiatedependent individuals," International Journal of Nursing Studies, vol. 48, no. 10, pp. 1244-1257, 2011.

[60] J. De Maeyer, W. Vanderplasschen, and E. Broekaert, "Exploratory study on drug Users' perspectives on quality of life: more than health-related quality of life?" Social Indicators Research, vol. 90, no. 1, pp. 107-126, 2009.

[61] B. Fischer, J. Rehm, G. Kim, and M. Kirst, "Eyes wide shut?-a conceptual and empirical critique of methadone maintenance treatment," European Addiction Research, vol. 11, no. 1, pp. 1-9, 2005.

[62] W. A. Anthony, "Recovery from mental illness: the guiding vision of mental health service system in the 1990s," Psychosocial Rehabilitation Journal, vol. 16, no. 4, pp. 11-23, 1993.

[63] E. Broekaert, "What future for the therapeutic community in the field of addiction? A view from Europe," Addiction, vol. 101, no. 12, pp. 1677-1678, 2006.

[64] W. N. Welsh and P. N. McGrain, "Predictors of therapeutic engagement in prison-based drug treatment," Drug and Alcohol Dependence, vol. 96, no. 3, pp. 271-280, 2008.

[65] M. L. Hiller, K. Knight, C. Leukefeld, and D. D. Simpson, "Motivation as a predictor of therapeutic engagement in mandated residential substance abuse treatment," Criminal Justice and Behavior, vol. 29, no. 1, pp. 56-75, 2002.

[66] S. J. Bahr, A. L. Masters, and B. M. Taylor, "What works in substance abuse treatment programs for offenders?" The Prison Journal, vol. 92, no. 2, pp. 155-174, 2012.

[67] S. G. Mitchell, R. Morioka, H. S. Reisinger et al., "Redefining retention: recovery from the patients perspective," Journal of Psychoactive Drugs, vol. 43, no. 2, pp. 99-107, 2011.

[68] M. F. Brunette, K. T. Mueser, and R. E. Drake, "A review of research on residential programs for people with severe mental illness and co-occurring substance use disorders," Drug and Alcohol Review, vol. 23, no. 4, pp. 471-481, 2004.

[69] C. Gagne, W. White, and W. A. Anthony, "Recovery: a common vision for the fields of mental health and addictions," Psychiatric Rehabilitation Journal, vol. 31, no. 1, pp. 32-37, 2007.

[70] W. Vanderplasschen, M. Bloor, and N. McKeganey, "Long-term outcomes of aftercare participation following various forms of drug abuse treatment in Scotland," Journal of Drug Issues, vol. 40, no. 3, pp. 703-728, 2010.

[71] K. E. McCollister, M. T. French, M. L. Prendergast, E. Hall, and S. Sacks, "Long-term cost effectiveness of addiction treatment for criminal offenders: evaluating treatment history and reincarceration five years post-parole," Justice Quarterly, vol. 21, no. 3, pp. 659-679, 2004.

[72] A. B. Laudet, "The road to recovery: where are we going and how do we get there? Empirically driven conclusions and future directions for service development and research," Substance Use and Misuse, vol. 43, no. 12-13, pp. 2001-2040, 2008.

[73] E. Broekaert, M. Autrique, W. Vanderplasschen, and K. Colpaert, “The human prerogative': a critical analysis of evidencebased and other paradigms of care in substance abuse treatment," Psychiatric Quarterly, vol. 81, no. 3, pp. 227-238, 2010. 


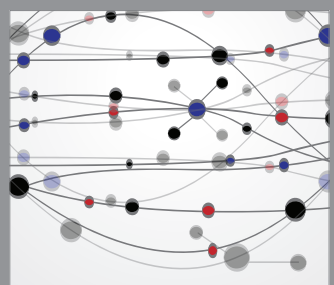

The Scientific World Journal
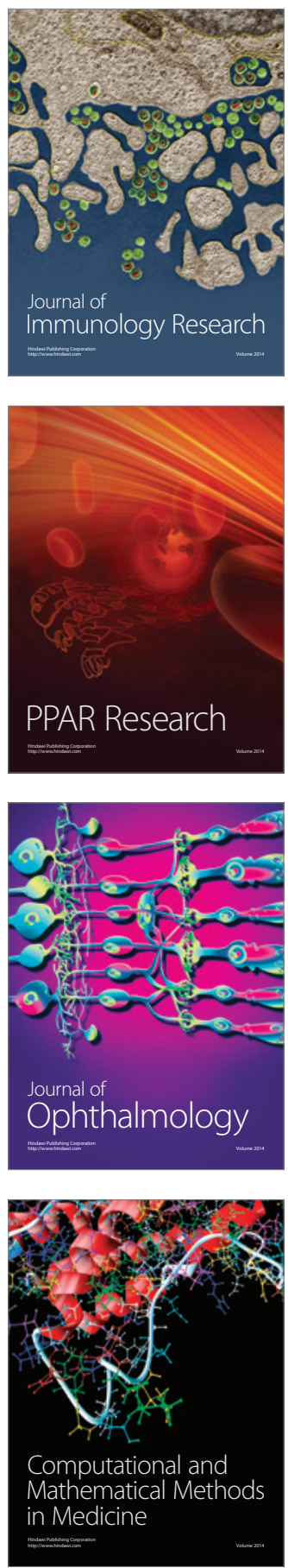

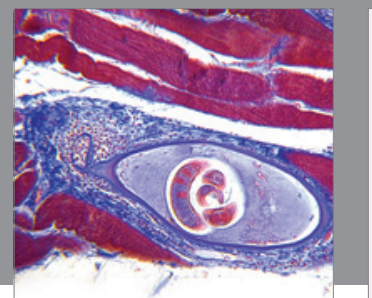

Gastroenterology

Research and Practice
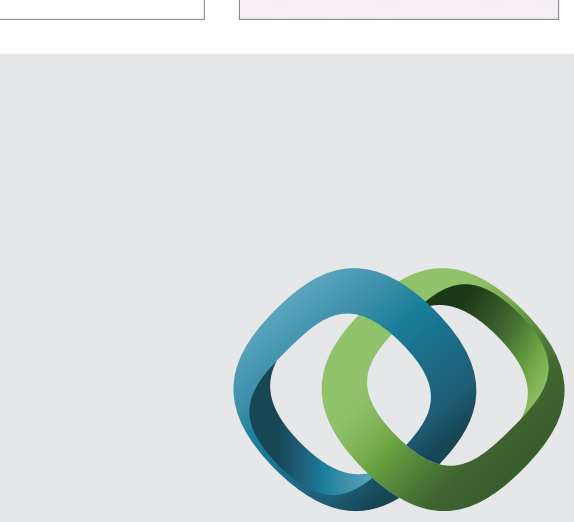

\section{Hindawi}

Submit your manuscripts at

http://www.hindawi.com
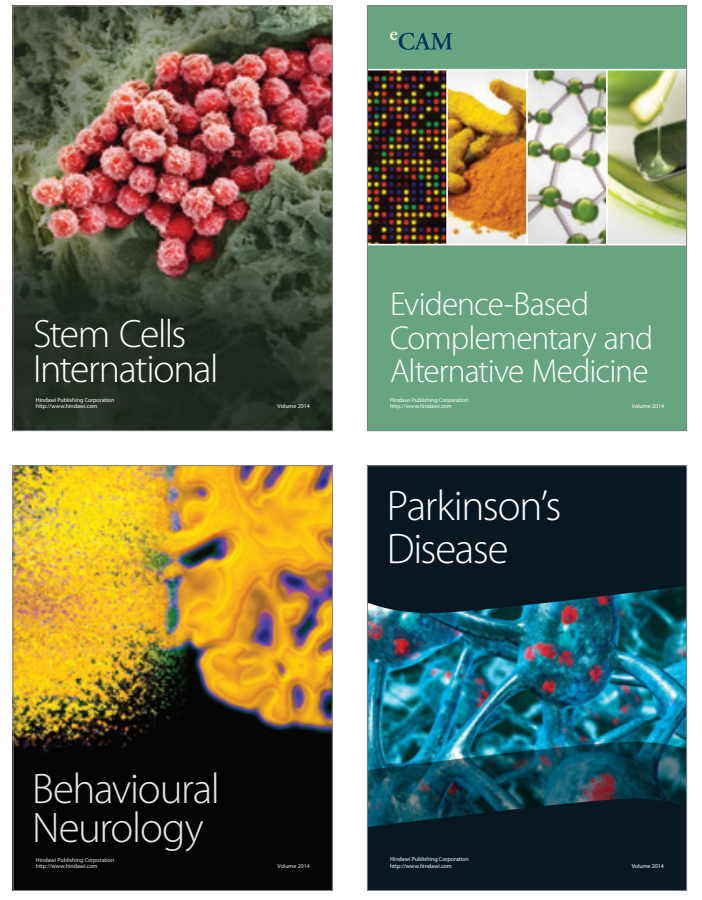
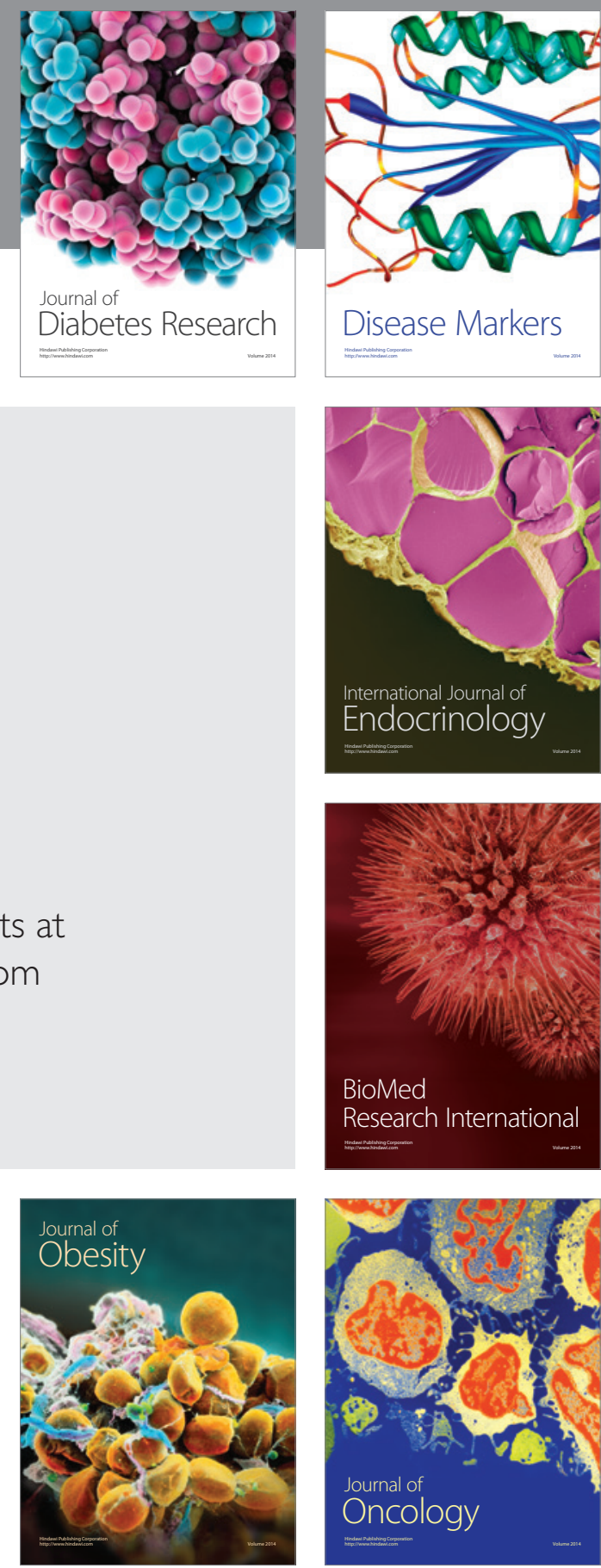

Disease Markers
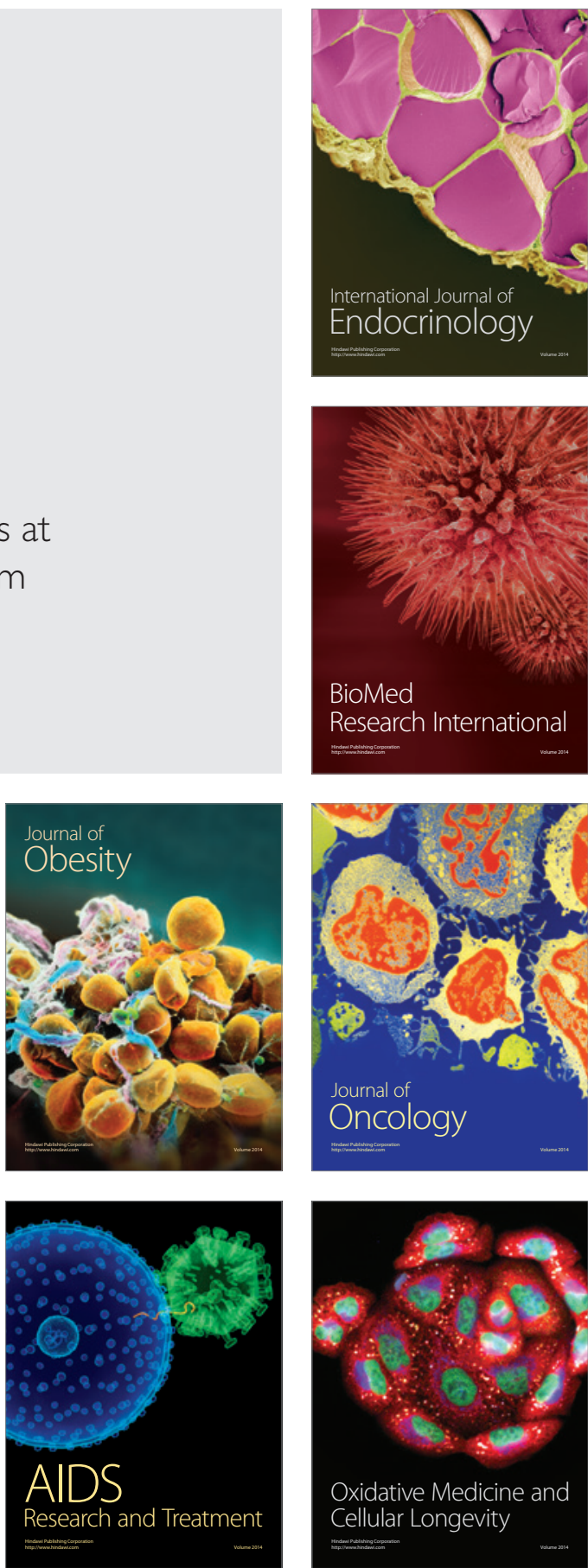